\title{
Childbirth Complications among Adolescent Mothers at Mbala General Hospital in Mbala District, Zambia
}

\author{
Chansa Regina, Maimbolwa M. Margaret, Catherine Ngoma, Mwaba S. Chileshe \\ School of Nursing Services, The University of Zambia, Lusaka, Zambia \\ Email: reginachansa@yahoo.com
}

How to cite this paper: Regina, C., Margaret, M.M., Ngoma, C. and Chileshe, M.S. (2019) Childbirth Complications among Adolescent Mothers at Mbala General Hospital in Mbala District, Zambia. Open Journal of Nursing, 9, 629-675.

https://doi.org/10.4236/ojn.2019.97051

Received: April 19, 2019

Accepted: July 19, 2019

Published: July 22, 2019

Copyright $\odot 2019$ by author(s) and Scientific Research Publishing Inc. This work is licensed under the Creative Commons Attribution-NonCommercial International License (CC BY-NC 4.0). http://creativecommons.org/licenses/by-nc/4.0/

\section{Open Access}

\begin{abstract}
Aim: The study aim was to explore childbirth complications among adolescent mothers at Mbala General Hospital, Zambia. Method: A descriptive cross-sectional study design of 138 adolescent mothers aged between 10-19 years was carried out over a period of five months at a referral hospital (Mbala General Hospital) in Mbala District, in the Northern Province of Zambia, Central Africa. Results: Maternal age prevalence was $31.1 \%$ for all admissions. The childbirth complications identified on admission were prolonged labour (42\%); during Labour-Cephalopelvic Disproportion (CPD) (59.7\%), prolonged labour $(20 \%)$, in the post-partum period, Post-Partum Hemorrhage $(\mathrm{PPH})$ due atonic uterus at $20 \%$. The most prevalent co-morbidity was Anemia (55.6\%). A statistically significant association was observed between childbirth complications and parity with a P-value of 0.001 . Conclusion: Our study demonstrates an association between childbirth complications and parity while the childbirth complications of prolonged labour, Contracted Pelvic Disproportion, premature rupture of membrane and $\mathrm{PPH}$ were observed.
\end{abstract}

\section{Keywords}

Childbirth Complications, Co-Morbidities, Adolescent Mothers

\section{Introduction}

Childbirth complications occur among adolescents girls aged $10-19$ years, and usually this occurs in 20 percent of cases and may affect the mother, foetus or both [1]. At least 16 million girls of this age group give birth every year [2] [3]. Childbirth is considered to be a normal physiological process. According to [4], the five major causes of complications of childbirth that may end up in morbidi- 
ties and mortalities are hemorrhage, infection, unsafe abortion, hypertensive disorders of pregnancy, and obstructed labour.

Studies such as [3] [5] [6] [7] show that complications of pregnancy and childbirth among adolescents are the leading cause of morbidity and mortality. For example, 70,000 adolescent girls die annually due to birth complications [8]. According to the United Nations (UN), 210 maternal deaths per 100,000 live births occur among adolescent mothers [9] [10], states that the risk of maternal mortality is more than twice high of adolescent girls aged 15 than those aged 25 to 30 years.

In Sub-Saharan Africa, the pregnancy and birth proportion for adolescent mothers is more than $50 \%$ [11], [6] [11] [12] reports that an estimated 1.42 million adolescents die every year and tens of millions of these have health problems emanating from complications of childbirth. "[9]" also states that sub-Saharan Africa death rate is about $500 / 100,000$ and that is the highest in any region across the world.

Zambia is graded fifth in adolescent birth rate in the region [13]. Thirty-five percent (35\%) of young rural girls give birth by the age of 18 year [14]. The percentage of adolescent pregnancy increases rapidly with age, from 5\% among women aged $15 \%$ to $59 \%$ among women aged 19 years [15]. According to [16], early pregnancies contribute to severe complications for the mother and may end up in morbidities and or mortalities. "[17]" also recorded that adolescents face higher reproductive risks leading to death or if not, complications of childbirth and unsafe abortion.

According to medical audits from around the globe, more than 80 percent (\%) of maternal deaths and disabilities are preventable and depend on the quality of care during labor and delivery, identification of problems, care and appropriate referrals to health facilities [18]. In view of this, the Zambian government put measures to combat effects of birth complication in childbearing women such as 1) Eight (8) visits of antenatal care; counselling and commencement of option $\mathrm{B}+$ to HIV positive mothers [19], 2) coverage of comprehensive Emergency Obstetric Care (EMOC) as an operative measures for complicated deliveries, 3) implementation of the training policy to sponsor and train Midwives in maternal and child care for every woman to access skilled birth attendant [20] and 4) training of all midwives country-wide in Helping Mother Survive Bleeding after Birth (HMSBAB) and Helping Baby Breath (HBB). The interventions appear to have had little impact on childbirth complications in adolescent mothers as shown by recent statistics of the institution Health Information Management Systems (HIMS) recorded between 2011 and 2015. A total of 2396 deliveries were conducted on adolescents from different referral centers in the district (Table 1).

However, it is not clear which type of complications are common to this age group, hence the study to explore childbirth complications and risk factors among adolescents to identify gaps that Mbala district may be facing. In this 
Table 1. Total number of complicated deliveries for the period covering 2011-2015.

\begin{tabular}{cccc}
\hline Year & Total No. of Deliveries & Adolescent Deliveries & $\begin{array}{c}\text { Total number of complicated } \\
\text { deliveries }\end{array}$ \\
\hline 2015 & 1808 & 590 & $585(169)$ \\
2014 & 1566 & 421 & $526(98)$ \\
2013 & 1738 & 522 & $571(131)$ \\
2012 & 1539 & 539 & $527(71)$ \\
2011 & 1349 & 324 & $423(127)$ \\
Totals & $\mathbf{8 0 0 0}$ & $\mathbf{2 3 9 6}$ & $2632(595)$ \\
\hline
\end{tabular}

Source: Mbala general hospital data base. Note: The figures in brackets are complications that occurred among adolescents for each year.

regard, sampling the only referral hospital in the district may aid in identifying gaps in the continuum of care to mitigate the impact of complications of childbirth among adolescents thereby improving the birth outcome in cases where complications of childbirth occur. As a district, it appears there was inadequate information on the study that had isolated adolescents' childbirth complications and generally, in Zambia, there is scarce information documented on the phenomenon. Therefore, it is hoped that the investigation on the phenomenon may help analyze these complications and risks to provide information that can be used to further improve the social, obstetric and postnatal care in the clinical area. It may also provide factual evidence concerning the phenomenon under study and also highlight specific variables to consider for follow up (further) studies. This, in turn, may facilitate adjustment in policy formulation consideration and implementation leading to having healthy people who are productive and adequately contributing to the national basket as well as competing favorably at the global level.

\subsection{Statement of the Problem}

Early pregnancies are known to contribute to severe childbirth complications for the adolescent mother, and that young maternal age predisposes or is a risk factor associated with childbirth complications [21]. In some cases, these lead to mortalities and or morbidities such as hemorrhage, unsafe abortions, infection, and hypertensive disorders and obstructed labour [6] [22] [23]. According to [24], the maternal mortality rate for adolescent mothers in the age group $15-19$ is 4.2 percent from the maternal mortality ratio of 398 per 100,000 live births for all women in child-bearing age. "[25]" states that, one (1) out of four (4) adolescent females aged between 15 - 19 years were married before the age of 19 years in Zambia. In Mbala district, early pregnancies are common in girls' age of 15-19 years or less especially those who drop out of school. Some become pregnant because they engage in unprotected sex at an early age as noted in the [26] which says, "Zambian young girls are less likely to use condoms" as this act is culturally considered a taboo for young girls who are not married. The evidence of early pregnancies is seen from the 2396 deliveries conducted among adolescent 
mothers for the period covering 2011-2015. Twenty-five percent (25\%) of 2632 childbirth complication were among adolescents. Arising from such conducts mentioned above and others, such number of deliveries among adolescent mothers leads to morbidity and mortality and this may pose serious health problems for this age group. If not addressed these morbidities and mortalities for mother may strain the nation's resources and can drain the country's economy as more resources will be channeled to the health sector to procure medical logistics and drugs [27]. The true cost of Maternal Death: Individual, tragedy impacts on family, community and nations. Therefore, the investigator sought to explore common childbirth complications among adolescent who gave birth at Mbala General Hospital (MGH).

\subsection{Justification of the Study}

The study generated knowledge that may lead to streamline and address adolescents' birthing care needs as a nation. It has also highlighted the gaps on which the institution may base their decisions to improve care in the clinical setting. Besides, the study will contribute to the body of knowledge and provide a significant basis for further studies. It also identified the childbirth complications and factors peculiar to Mbala as a rural district which may not be common in other settings in Zambia. Furthermore, the study has provided information that may help to substantiate the importance of the specific needs on adolescents' rights highlighted in [28]. Additionally, adolescents in Zambia need serious attention that is specific to their reproductive (birthing) needs and address other healthrelated problem which this study has highlighted. Consequently, this may make a contribution towards the attainment of Sustainable Development Goal (SDG) number three (iii) which states "health for all at all ages".

\section{Theoretical Framework-McCarthy and Maine (1992) Framework of Analysis}

The study was guided by the adapted and modified McCarthy and Maine (1992) Framework of Analysis of determinants of maternal mortality. The framework looks at cultural, social, economic, behavioral and biological factors that influence maternal mortality, that is:

1) Reduce the likelihood that a pregnant woman will experience serious complications of pregnancy and childbirth

2) Improve the outcome of the woman with childbirth complications

3) Availability of an efficient referral system to cater for EmoC services must be in place [29].

McCarthy and Maine (1992) framework of analysis is applicable to this study that sought to explore childbirth complications among adolescent mothers. (Figure 1) The complications include both medical and obstetric conditions that occurred during labour, delivery and immediate postpartum period.

This implies that, birth preparedness, early detection of childbirth complications and appropriate management can positively impact on maternal health. 


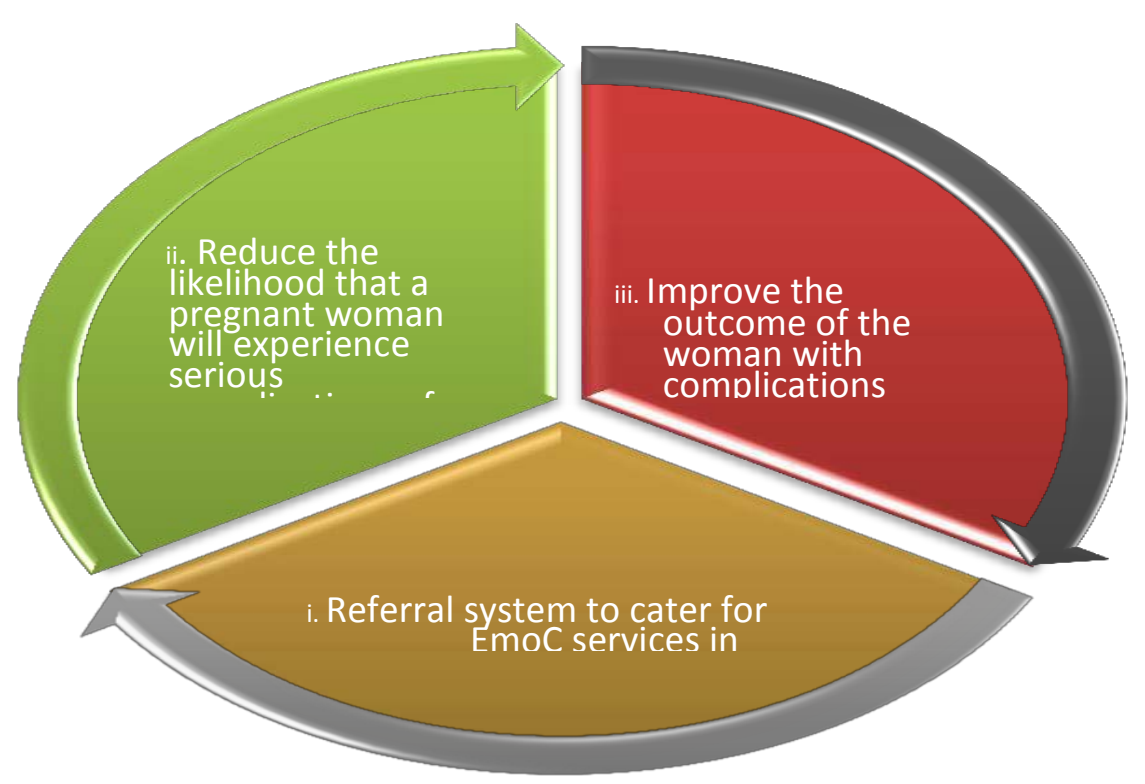

Figure 1. McCarthy and Maine (1992) framework of analysis. A modified frame work adapted from [29].

Secondly, availability of effective referral system, intensifying monitoring skills to detect childbirth complications at all levels of the service delivery (Health institutions) by skilled personnel will promote optimal health for laboring adolescent mothers.

1) To reduce the likelihood that a pregnant adolescent will experience serious complications of childbirth well in labour and thereafter.

The adolescent mother's age and parity have a significant effect on birth complications that may lead to long term disabilities. Young mothers may develop complications during labour and delivery because their biological and physical make-up is still underdeveloped [30]. Complications like pre-eclampsia/eclampsia, anemia and obstructed labour [9] are more common in primigravidas/primipara.

2) Improve the outcomes of adolescent women with childbirth complications.

The process of care during labour, delivery and after delivery to diagnose and institute appropriate interventions is vital and is of great significance for the survival of the adolescent mother [31]. To monitor young mothers during Antenatal Care (ANC), labour and delivery diligently, and to rule out complications and other risks such as short stature or big baby that may lead to Cephalo-pelvic disproportion (CPD). Should complications occur during labour or delivery, the midwife and doctors work in collaboration to prevent adverse outcomes and minimize incidences of both morbidity and mortality for the mother.

3) Availability of an efficient referral system to cater for EmoC services in place.

Consequently, socio-demographic factors such as residential area (distance), marital status and level of education may lead to birth complications in adoles- 
cents. Distance to health facilities (good road infrastructure), an effective referral system and access to skilled attendants to detect obstetric complications are vital in promoting health in adolescent mothers. Therefore, close monitoring during labour [6] and use of partograph is vital to detect deviations of normal progress of labour. Secondly, early diagnosis and referral do help improve the outcomes of adolescent women with childbirth complications. The framework provided guidance in the formulation of questions for the questionnaire and in analyzing the variables associated with common childbirth complications among adolescent mothers.

\subsection{Research Question}

What are the childbirth complications among adolescents aged $10-19$ years who gave birth at Mbala General Hospital?

\subsubsection{General Objective}

To explore childbirth complications among adolescent mothers aged 10 - 19 years who gave birth at Mbala General Hospital, Zambia.

1) Specific Research Objectives

a) Identify childbirth complications among adolescents who gave birth at Mbala General Hospital.

b) Determine Socio-Demographic characteristics and age prevalence associated with childbirth complications in adolescent mothers who gave birth at Mbala General Hospital.

c) Determine co-morbidities associated with childbirth complications among adolescents who gave birth at Mbala General Hospital.

2) Research Questions

a) What are the childbirth complications among adolescents who gave birth at Mbala General Hospital?

b) What are the Socio-Demographic characteristics and age prevalence associated with childbirth complications in adolescent mothers who gave birth at Mbala General Hospital?

c) What are the co-morbidities associated with childbirth complications among adolescents who gave birth at Mbala General Hospital?

\subsubsection{Conceptual Definitions of Terms}

1) Adolescent-a young person between the ages 10 to 19 years [6].

2) Adolescent mother-a young woman, below the age of eighteen who became pregnant, gave birth to a child and chose to raise the child [32].

3) A Complication-means a secondary disease or condition that develops in the course of a primary disease or condition and arises either as a result of it or from independent causes [33].

4) Risk Factor-something that makes a person more likely to get a disease or condition [34].

5) Co-morbidity is the presence of more than 1 distinct condition in an indi- 
vidual [35].

6) Patient a person who is receiving medical care

https://dictionary.cambridge.org/us/dictionary/english/patient.

\subsubsection{Operational Definitions}

7) Adolescence - a transitional stage of physical and mental human development, involving biological, social and psychological changes, occurs between 10-19 years of age; putting an adolescent at risk for early marriage, unwanted pregnancies and birth complications.

8) Adolescent mother-any woman between 10 and 19 years who has delivered a baby irrespective of gravida, parity, neonatal outcome or marital status.

9) Complications-any diagnoses reported from the start of labour, delivery until (first - six days) days postpartum related to birthing; and that had adverse effect on the mother, altering functional abilities of the activities of daily living in the adolescent mother such as Severe preeclampsia, Eclampsia, CPD, Preterm labour, Pre-rupture of Membranes (PROM), Poor fetal growth, Fetal distress, Ante Partum Hemorrhage (APH), Poor progress, prolonged latent phase) Cord prolapse, Malpresentation (transverse, Breech, compound presentation, Ruptured uterus, Placenta Previa/abruptio, Retained Placenta/Retained products, Third degree, perineal tear and Postpartum Hemorrhage (PPH).

10) Risk Factor-any medical or surgical condition or disease that co-exists with pregnancy or labour and influence or altered patients' normal labour or delivery processes

11) Co-morbidities such as: Anemia, Malaria, Human Immunoglobulin Virus infection, Urinary tract infection, Diabetes Mellitu.

12) Patient is any adolescent woman in labour between 10 - 19 years who develops childbirth complication.

\subsubsection{Study Variables and Cut-Off Points}

1) Dependent Variable

Childbirth complications among adolescents.

2) Independent Variables

a) Age, b) Residential area, c) Marital status, d) Education level, e) Antenatal care, f) Parity, g) Health status (Co-morbidities).

\section{Literature Review}

\subsection{Introduction}

This chapter is a review of literature related to the topic that is, studies conducted on complication of deliveries in adolescent mothers. The Literature reviewed was taken from research engines and databases such as Pub medical central (PMC), Bio-Medical Central (BMC), Medline and Google Scholar, Google books, Medline, online journals and others. The review process has broadened the knowledge of the investigator about the phenomenon to know what other researchers have done. 
According to [35], literature review deals with "identification, location and analysis of documents" (p. 65) with information related to the problem under investigation. The literature review in this study focuses on studies conducted on childbirth complication in adolescent mothers in Europe, some African Countries and within Zambia. The Literature review follows the sequence of questions as arranged in the schedule as childbirth complications in adolescents, Socio-demographic characteristics associated with childbirth complications and risk factors associated with childbirth complications in adolescent mothers.

\subsection{Overview of Childbirth Complications in Adolescents}

The first objective looked at childbirth complications that occur in adolescents girls aged 10 - 19 years. Studies conducted both in developed and developing countries raise questions on whether there is a relationship between socio-demographic characteristic age and childbirth complications in adolescent mothers due to physiological immaturity and other factors that may result in poor birth outcomes in adolescent mothers [36]. The major complication noted among adolescents and led to morbidities and or mortalities were hypertensive disorders, hemorrhage, infection, abortion and obstructed labour [6].

\subsection{Childbirth Complications in Adolescents}

In a study conducted in Mexico by [37], complications during pregnancy were estimated to be at 26 percent (\%) in adult women and 10 percent (\%) in adolescents $(\mathrm{p}=0.04)$. However, the gestational age and birth-weight were similar in both groups. The study further revealed that birth by cesarean section was more frequent among the offspring of adult women ( $65 \%$ compared to $48 \%, p=0.015$ ) than in adolescents.

"[38]" in Cameroon revealed that there was a high rate of adolescent pregnancies which as a result of anatomical and physiological immaturity caused many birth complications in adolescents. This was also replicated in a study conducted in Brazil by [39] which revealed that hypertensive disorders of pregnancy, Anemia and gestational diabetes and delivery complications determine increase in maternal mortalities from the biological point of view of adolescence pregnancy. This shows that anatomical and physiological immaturity may lead to high birth complications in adolescents.

However, a study conducted in India by [40] showed a higher proportion (65.7\%) of adolescent mothers having had normal vaginal delivery compared to the older mothers at (61.4\%). According to the above-mentioned study, a higher proportion of normal vaginal delivery in adolescents compared to the older mothers could have been attributed to a higher proportion of smaller babies in the adolescent mother age-group. The same study also showed that about $34 \%$ of the adolescent mothers had instrumental delivery (forceps and caesarean) compared to $39 \%$ of the adult mothers. This result renders one to question whether age can increase birth complications if $65.7 \%$ of adolescent mothers had normal 
vaginal deliveries though they had small for gestational age (SGA) babies, hence the need for this study.

Reference "[41]" conducted a study to determine whether adolescent mothers were at higher risk of maternal and perinatal adverse outcomes compared with mothers aged 20-24 years in low resource settings in six Central African countries namely, Kenya, Zambia, India, Pakistan, Guatemala and Argentina. The results of the study actually showed that adolescents did not show an increased risk of maternal adverse outcomes when compared to adults. However, It showed risks of preterm birth and LBW being significantly higher among both early and older adolescents, with the highest risks observed in the $<15$ years group. To establish whether this was the case in Mbala is what this study sought to establish.

\subsection{Socio-Demographic Characteristics Associated with Childbirth Complications in Adolescents}

\subsubsection{Age}

In the United States, [42] conducted a study to examine associations between maternal age and prevalence of maternal morbidity during complications of labor and delivery. In this study, the age group that had the highest odds for complications were those aged $11-18$ years compared to those who were $25-29$ years old.

Complications involved included preterm delivery, Chorioamnionitis, endometritis, and mild pre-eclampsia. In the same study, the 15 - 19 year-olds, had greater odds for severe pre-eclampsia, eclampsia, post-partum hemorrhage, poor fetal growth and fetal distress. This is in line with a prospective, case-control study conducted in Al-Basra General hospital by [43] on pregnancy complications and outcome among adolescent mothers whose results revealed high frequency of pregnancy complications in both groups' of adolescents and adults. There was a significant increase in the incidence of spontaneous preterm labour in women aged 15 - 19 years in comparison to women aged 20 - 24 years (15.5\% versus $4.3 \%)$. However, findings in a study conducted in Hong Kong by [44] which compared the under 19 years with the 20 - 29 years, revealed that there was no difference in induction of labour and primary postpartum hemorrhage in both groups. The other indication was for caesarean section which showed that the study group had a significantly lower incidence of instrumental deliveries for prolonged second stage of labour than the reference group. Other findings were that there was no difference for incidence of caesarean section for failure of the progress of labour in both the study and the reference group. This showed that age may or may not be associated with childbirth complications related to anatomical and physiological immaturity a case this study would want to establish in Mbala.

Secondly, bodily immaturity is known to contribute to birth complications in adolescent mothers-Chadwick and Foster, in [9]. The progress report given by [45] in Geneva and Switzerland also revealed that adolescents' pregnancies for 
those aged 15 - 19 years' and especially for the younger adolescents (less than 15 years) carries increased risk of pregnancy and childbirth complications resulting from underlying biological factors such as gynecological immaturity and incomplete pelvic growth. The study further revealed that pregnant adolescents have risks such as malnutrition, Anemia, malaria and sexually transmitted infections plus HIV/AIDs. For example, a study by [41] in Sub Saharan Africa shows that pregnancy predisposes adolescent mothers to pregnancy-related complications such as obstructed labour and maternal deaths in relation to biological immaturity of the adolescent mothers.

Reference "[40]" adds that adolescent pregnancies represent a high-risk group in reproductive terms because of the double burden of reproduction and growth. This is in line with a study conducted in Ethiopia by [4] which sought to establish the Prevalence of Obstructed Labor among Mothers Delivered in Mizan-Aman General Hospital. The study revealed that obstructed labour was one of the leading causes of complications of childbirth among women aged between 15 and 19 years in Sub-Saharan Africa and Southeast Asia. Others were hemorrhage, infection, unsafe abortion and hypertensive disorders of pregnancy. Other studies by [46] [47] in South Africa revealed that pregnancy in very young women is generally considered to be a very high-risk event, because adolescent girls are physically and psychologically immature for reproduction. Whether this was the case in Mbala was in part the interest of this study.

However, some of the studies conducted both in developed and developing countries disputed the relationship between age and birth complications in adolescent mothers occurring as a result of physiological immaturity. For example, results of the study by [36] in USA was not clear as to whether the poor birth outcomes of adolescent pregnancy were related to the biological immaturity leading to adverse birth outcomes. In Mbala district, as well, the question remains whether age contributes to birth complications in adolescent mothers, hence the need for this study to explore the phenomenon.

In another study conducted in Sub Saharan Africa by [48] to identify groups at higher negative risk for pregnancy outcomes among adolescents and adults' pregnant women, results revealed the prevalence of low birthweight infants and preterm delivery of $10 \%$ of $371 / 3851$ and $4 \%$ of $159 / 3862$, among mothers aged $\leq 16$ years at (1.96; $95 \%$ CI 1.35 to 2.83 and or: 2.62 ; $95 \%$ CI 1.59 to 4.30 ) respectively.

In Zambia, [49] conducted a study on adverse obstetric outcomes in adolescent pregnancy in rural Zambia, The findings revealed that adolescents under the age of 16 years had the highest rates for eclampsia (23.8\%), hemorrhage (6.0\%), CPD (36.7\%), prolonged labour (7.1\%) and caesarean section (43.9\%) compared to their older counterparts. With regards to perinatal outcomes, rates of LBW, pre-term delivery and low Apgar score were highest among mothers aged 10-15 years. This is in line with the Demographic Health Survey by [50], which stated that adolescent pregnancy and child birthing are higher in rural 
areas (37\%) than urban areas (20\%). Furthermore, [51] also reported that "every 3 in $10(30 \%)$ young women age 15 to 19 years have either given birth or may be carrying a pregnancy". [15] also stated that (28.5\%) of girls aged 15-19 have had been pregnant or had a live baby. This shows that childbirth among adolescents starts quite early in Zambia. Therefore, in this study the investigator wants to determine the prevalence of maternal age among adolescents in Mbala District.

\subsubsection{Residential Area}

In Finland, [52] in his study which looked at adolescent birth complications, found that $(16 \%(n=1168)$ of 7305 adolescent mothers lived in rural areas. This may suggest that living in rural areas may be a factor that leads to complications as many adolescent mothers may have limited access to health facilities and services. This had earlier been shown by a study conducted by [53] in South Africa whose results indicated that distance to the health facility and the failure to seek care or delay in doing so resulted in $54.1 \%$ of adolescent maternal deaths in South Africa alone.

Another study conducted by [54] in Kenya also revealed that an increase in distance to the nearest healthcare facilities was associated with fewer antenatal visits. Other studies conducted in Zimbabwe by [55] [56] in Pakistan found that uncomfortable transport, poor road conditions and difficulties in crossing big rivers contribute to delays in seeking health care. This was also revealed in studies such as [57]; [58] which found higher incidences of poor pregnancy outcomes among rural adolescent mothers than their urban counterparts. Therefore, residence has been cited as a risk factor in adolescent pregnancy that may lead to complications and this study will look at this to establish as to whether distance to the health facility would be one of the factors that may be associated with childbirth complications in adolescents in Mbala district.

\subsubsection{Marital Status}

In Canada, [59] conducted a study which looked at socio-demographic characteristics of adolescents who become pregnant. In this study, it was established that adolescent mothers in developed regions such as North America and Western Europe tend to be unmarried and that adolescent pregnancy is seen as a social issue. On the contrary, adolescent parents in developing countries are often married. For example, early (child) marriages are traditionally approved in some cultures such as Pakistan [60], and have an adverse impact on maternal mortality and morbidity. Similarly, studies conducted by [6] [7] indicated that Nepal in India has as higher adolescent births amongst the childbearing women. The study recorded that 23 Percent (\%) of 23 millions' of Nepalese population are given in marriage as adolescents; and the median age at first marriage for ever married women in Nepal is sixteen and a half $(161 / 2)$ years. This indicates that the majority of newly married couples are adolescents. These variations may suggest that early pregnancy may bring in socio-economic challenges that may lead to stress on the expecting adolescent and consequently lead to serious birth 
complications. Other implication on the socioeconomic situation is of adolescent motherhood as these mothers may have little or no resources for a health and safe motherhood. At times they may not have prepared adequately for birth (birth preparedness) in case of emergencies because they are not economically independent. Hence, this study will try to establish whether marriage status of adolescent mothers contribute to childbirth complications in Mbala District.

\subsubsection{Level of Education}

Reference "[6]" report on adolescent pregnancy, low education levels are closely associated with early childbearing in adolescent girls between 15 to 19 years. Low literacy and education levels render expression inability of this age-group to comprehend the risks involved in being pregnant at a tender age and the consequential outcomes. This is in line with the results obtained in a study conducted by [61] in India on Feto-maternal outcome in adolescent pregnancy. The findings of the study revealed that, out of 303 adolescents 48 (15.8\%) were illiterate, $200(66 \%)$ had primary education, $52(17.1 \%)$ had secondary education and only $3(0.9 \%)$ studied up to higher secondary. None had attained college-level education. This may have implications on one's ability to refrain from socio-vices that may lead to early pregnancy and eventually maternal delivery complications may occur.

Another study by [40] in India revealed high levels of illiteracy to be associated with adolescent pregnancy and complications. In this study, all the 350 participants (100\%) and 394 (98\%) in the control group had low educational levels. Therefore, this study wants to validate whether education level and literacy status may be associated with childbirth complications in Mbala district as well.

\subsubsection{Antenatal Visits}

A study conducted by [62] in Sri Lanka showed that the use of antenatal care offers opportunities for reaching pregnant women with interventions that are vital to their health and wellbeing and that of their infants. This is in line with [63] whose results revealed that researchers had evidence for adopting Focused Antenatal Care (FANC) strategy. The evidence showed that prenatal care helps to decrease adverse pregnancy outcomes for adolescent pregnant women by reducing risk factors through education and social support. Furthermore, studies such as [64] [65] observed that Antenatal care (ANC) services recommended interventions to reduce maternal mortality and is concerned with achieving optimal health outcomes for the mother. On the other hand, [66] high light some of the activities done at ANC as early detection of complications and prompt treatment; micro-nutrient supplementation; birth preparedness and complication readiness; and health promotion and disease prevention that supports the evidence mentioned above. Nevertheless, a study conducted by [48] in Zimbabwe, revealed that there was a weak relationship between pregnancy and knowledge of complication of pregnancy among adolescent mothers. This lack 
of knowledge by adolescent mothers that may be attributed to low educational levels could be the reason why adolescent mothers who become pregnant at a tender age may end up with childbirth complications. This means that knowledge of childbirth complications that come with early pregnancy may help adolescent mothers to refrain from sexual activities or may make use of preventive measures like use of condoms if they cannot abstain, to prevent pregnancies at an early age. Reference "[67]" sums it up by stating that young parents tend to have poorer access to maternity services and poorer outcomes than older parents. Therefore, establishing whether adolescents had attended ANC where knowledge on childbirth complications that come with early pregnancy is given routinely is in part what this study sought to establish in this age group as this may help reduce childbirth complications in adolescents when they learn of the consequences of giving birth as an adolescent may at times end in complications.

On the contrary, other researchers such as [64] [68] for example, the "Prenatal Care Initiation among Pregnant Teens in the United States" noted that lack of access to prenatal care is a socioeconomic factor that is linked to higher rates of low-birth-weight children and other complications such as maternal deaths. Therefore, the investigator wanted to find out if adolescents in Mbala who developed childbirth complications had poor access to maternity services or had other co-founding factors related to socio-economic status.

\subsection{Co-Morbidities}

In Finland, [69] conducted a study that sought to establish if teenage pregnancy was an obstetric risk in a welfare society and found that there were significantly increased risks of anemia, eclampsia, proteinuria, Urinary Tract Infection (UTI) and pyelonephritis in the adolescent mothers aged 18 to 19 years of age. This seems to suggest that medical conditions may be a factor that may lead to birth complications in adolescent mothers.

Similarly, a study conducted by the [6] to establish whether health status presented any risk to adolescent mothers recommended that there was a need to be alert to special problems that require particular attention among adolescents. These included anemia, poor nutritional status, malaria, HIV and other sexually transmitted infections to mention a few. The organization also stated that access to services for preventing the mother to child transmission of HIV was key in the prevention of birth complication in adolescents. Whether attention was paid to address such precautions of co-morbidities in Mbala District is what this study sought to establish in order to relate or rule out any association with childbirth complications.

Another study by [70] in USA indicated that poverty was one of the risk factors that led to complications in adolescent mothers as they were likely to be malnourished a factor that contributes to poor pregnancy outcomes. This is in tandem with the results obtained in a study conducted by [71] in Pakistan where 
anemia was found to be the most common medical disorder among adolescent mothers at delivery with Hemoglobin $<10 \mathrm{gm}$ in $89(75 \%)$ of the 118 cases. This study, therefore, established whether poverty was one of the factors that lead to complications in adolescent mothers.

\subsection{Conclusion}

The studies have shown that marital status variations noted in different regions may cause different challenges and implication from a socio-economic point of view. It is also worth noting that other co-founding factor such as lack of knowledge of childbirth complications, and not only the ones being studied in this study may lead to birth complications in adolescents.

However, it appears that no study has been conducted on adolescent Mothers in Mbala district; and that there is limited evidence or scarce information documented on adolescent mothers and childbirth complications in Zambia. Therefore, it was felt that investigation on childbirth complications among adolescents and establishment of demographic characteristics associated with birth complication in Mbala District; would help to analyze these complications and provide information that could be used to further improvement of the social, obstetric and postnatal care. This may lead to having a healthy people in the district that are productive and adequately contributing to the national basket as well as competing favorably at the global level.

\section{Methodology}

\subsection{Introduction}

In this chapter, the focus was on research design, study settings, study population, selection of participants, inclusion criteria, exclusion criteria, sampling method, sample size, and instruments for data collection. The focus also was on data analysis, pilot study, and validity and reliability of data collection instrumental tool.

\subsection{Study Design}

The study used a descriptive cross-sectional study design. The study did not involve manipulation of the environment but recording of information as observed from the participants [72]. The design allowed the researcher to generate data regarding common childbirth complication prevalence and identification of high-risk groups among adolescent mothers in Mbala district to provide a picture of the burden of common childbirth complications and measure the prevalence of risk factors among adolescent mothers aged 10 - 19 years.

\subsection{Study Setting}

The study was conducted at Mbala General referral Hospital Obstetrics and Gynaecology (Maternity) wards. It was a 40 bed capacity with five units in one 
namely, delivery unit or Labour ward, post-natal, neonatal, Prem nursery unit and an eclampsia unit. It was the only second level referral Hospital in the district receiving patients from the health centers within and out of Mbala district. It also received referrals from Mungwi, Senga and Mpulungu districts. Mbala General Hospital is approximately 867 kilometers away from the capital city of Zambia, Lusaka and $167 \mathrm{~km}$ from the Provincial Capital Kasama. Its surface area covers about 10,832 $\mathrm{km}^{2}$ (Mbala District Health management Team-MDHMT, 2011-2013 Action Plan). Its occupants speak Mambwe and are involved in farming, they grow beans and groundnuts.

\subsection{Study Population/Selection of Participants}

The study participants were selected purposively by targeting adolescents from among women who came to deliver at the institute to come up with a sampling frame (List of participants). That is, all adolescent mothers from 10-19 years who gave birth at Mbala General Hospital from 15th June 2017 through to the time the sample size of 138 participants was obtained.

\subsubsection{Inclusion Criteria}

The inclusion criteria were (1) all adolescent with singleton or multiple pregnancies age 10 - 19 years.

\subsubsection{Exclusion Criteria}

The exclusion criteria 1) were all adolescents with loss of or termination of pregnancy; and 2) those that did not consent to participate in the study.

\subsection{Sampling Method}

A purposive sampling method was employed for this study. It involved no manipulation of the environment but information recording as was observed from the participants [72]. It was a non-probability sample that is selected on the basis of the characteristics of a population and the objective of the study [73]. This is used in the study when the researcher wants to reach the target quickly. Besides, it also looks at typical case characteristics. In this study, common childbirth complication among adolescent was the main concern. The reason for choosing this method was because it matches well with the cross-sectional design that is good for gathering data in a short period of time (snapshot) and oriented to specific characteristics of variables to be measured in the study [74]. It is also simple and cheap and can be analyzed using a variety of software like EPI INFO and SPSS. Data entry and statistical analysis were performed using SPSS version 24.0. Chi $=$ squire was used to find out the association between variables while Binary Logistic Regression was used to analyze the combined impact of the independent variables against the dependent variable. Furthermore, cross tabulation was done to test for statistical significance between childbirth complications and other variables such as age, residential area, and marital status, level of education and antenatal visits. 


\subsection{Sample Size}

The sample size calculation was adopted from [75] Tanzania (determined by WHO (1991) method as follows:

$$
N=t^{2} \times(p \times q) / d^{2}
$$

where,

$$
\begin{aligned}
& N=\text { sample size } \\
& T=\text { Marginal error }(1.96) \\
& P=\text { expected prevalence }(10 \%) \\
& Q=1-P(0.9) \\
& D=\text { Level of precision }(5 \%)
\end{aligned}
$$

Therefore, population size was the total number of deliveries among adolescent girls aged between 10 to 19 years as indicated in the hospital records for adolescent deliveries from 2011-2015.

The total number of adolescent deliveries for this period was 2396.

Margin of Error (Confidence Interval) - (5\%)

Confidence Level-95\%

Prevalence-0.9 (as adopted)

At $95 \%$ confidence interval $-\mathrm{Z}$ score $=1.96$

Formula:

Sample Size $=(\text { Z-score })^{2} \times$ Prevalence $\times(1-$ Prevalence $) /(\text { Margin of error })^{2}$

$N=(1.96)^{2} \times 0.10(1-0.10) /(0.05)^{2}$

$N=3.84 \times 0.10 \times 0.9 / 0.0025=138$

$N=138$ participants

\subsection{Data Collection}

The study used a modified structured interview schedule derived from data abstraction form adopted from National Fetal-Infant Mortality Review Program [76] Washington DC, and United Kingdom. It has information containing closed ended questions that are short statements, phrases and cues to guide the researcher to collect relevant data on socio-demographics, childbirth complications and observed risk factors in adolescents. It is divided into four sections arranged in sequentially and in a simple, concise, brief sentence or statements for easy understanding according to objectives. The same tool was used on all patients to validate consistence in data collection. The instrument was translated into a local language by an expert to cater for those who were unable to write or understand English. The interviews were conducted in the postnatal consultation room after the participants consent to the interview. The variables studied included Childbirth complications among adolescents as the dependent variable while age, residential area, marital status, education level, Antenatal care, parity and health status (co-morbidities) as the independent variables

Data were collected by the investigator and two (2) Bachelor of Science nurses who were trained to collect data. Furthermore, corrections on the tool were done after the supervisor scrutinized the questions to ensure that they were clear 
enough to provide information sought.

\subsubsection{Validity}

To ensure the validity of the research tool, the researcher conducted an exhaustive literature search to have adequate content coverage. External validity was sustained by ensuring that the required number of patients was interviewed. Internal validity was achieved by testing the data collecting tool through a pilot study conducted at Kasama General Hospital which had similar health services as Mbala General Hospital.

\subsubsection{Reliability}

Reliability focused on two aspects, which were stability and equivalence. The same interview schedule and method of collecting data was used on all the patients during the actual study.

\subsection{Data Collection Technique}

In this study, data were collected between 1st October 2017 and February 2018 using the modified structured interview schedule data abstraction form adopted from National Fetal-Infant Mortality Review Program [76] Washington DC, and United Kingdom. The research assistants were oriented to the data collection tool and the technique through a one-day course. To get the needed information from respondents, the researcher and the assistant introduced themselves to the health worker who was on duty and proceeded to the interview room. Later, they explained to participants the purpose of the study. After reassuring the respondents on confidentiality that no name was to appear on the questionnaire but that numbers were used on the interview schedule to help respondents feel comfortable and open to give correct answers. Upon consenting, each participant signed the consent form. The illiterate participants were asked to make a thumbprint. Instructions were read to the respondents and this was followed by asking the questions. Other information was collected by use of client's files. The client's files were reviewed to obtain information that clients may not be able to explain using the interview schedule. Asset forms were signed by guardians for adolescents below 18 years who by law are not able to make decisions on their own because they cannot make independent decisions. Respondent was encouraged to answer sincerely and truthfully. Other data which could not be given by the clients such as diagnostic test for hemoglobin level estimations, blood slides for malaria testing and urinalysis, etc. came from client records as a source of information. After each session, the interviewer thanked the client for the participation, and then the next respondent was invited in (see Appendix).

\subsection{Pilot Study}

The pilot study was done to determine the relevance and practicability of the data collection tool. Pretesting of the data collection tool was conducted at Ka- 
sama General Hospital on 10 percent of the total adolescent mothers of the study was used. The pilot study enabled the researcher to pretest the data collecting tool to elicit flaws and amend some questions such as; question 18 Answers (4) read "more than 12 hours" but changed to "more than 18 hours".

\subsection{Ethical Considerations}

Ethical clearance was sought from the University of Zambia Biomedical Research Ethics Committee (UNZABREC). Permission to conduct the study was further obtained from Kasama General Hospital. The purpose and nature of the study were explained to each participant. Those who declined to participate were reassured that no privileges would be taken away from them. Those who agreed to take part in the study were requested to sign a consent form for legal purposes and to authorize participation in the study. Participants were assured of anonymity and confidentiality by interviewing them in privacy individually as well as ensuring that participants' names did not appear on the interview schedules. Only the researcher and research assistants were allowed to have access to the research data.

\subsubsection{Beneficence}

The patients' decisions were respected and efforts were made to ensure their well-being throughout the data collection.

\subsubsection{Justice}

In the study, justice was upheld, by ensuring that all participants were treated equally and given an equal opportunity to make individual decisions on whether to participate in the study or not.

\subsubsection{Maleficence}

Patients were not subjected to any harm as the research did not involve any invasive procedures. They were protected from psychological harm by letting them answer the questions in a natural setting which provided privacy with no public interference.

\section{Presentation of Findings}

This chapter presents the findings of the study on childbirth complications at Mbala General Hospital. The study findings were based on the responses from 138 adolescent mothers who gave birth at Mbala General Hospital Labour Ward at the time of the study. The general objective of the study was to explore childbirth complications among adolescent mothers at Mbala General Hospital in Mbala district of Northern Province. The Findings are presented according to research questions as reflected in Chapter one: 1) What are the childbirth complications among adolescents who gave birth at Mbala General Hospital? 2) What are the Socio-Demographic characteristics associated with childbirth complications in adolescent mothers who gave birth at Mbala General Hospital? 3) What are the co-morbidities associated with childbirth complications among 
adolescents who gave birth at Mbala General Hospital?

Data was analyzed using SPSS version 22 and further presented using pie and bar charts as shown below.

\subsection{Childbirth Complications among Adolescents Who Gave Birth at Mbala General Hospital}

Table 2: A total of 444 mothers delivered during this time, out of which (138) $31.1 \%$ were adolescents. Of the total adolescents (81) 58.6\% developed complications at different stages of labour. The most common childbirth complications were Cephalo-pelvic disproportion (CPD) which accounted for 59.7\% (37)

Table 2. Variables, indicators and cut-off point.

\begin{tabular}{|c|c|c|c|c|}
\hline VARIABLE & $\begin{array}{l}\text { OPERATIONAL } \\
\text { VARIABLES }\end{array}$ & $\begin{array}{l}\text { CUT-OFF } \\
\text { POINT }\end{array}$ & INDICATORS & $\begin{array}{l}\text { QUESTION } \\
\text { NUMBER }\end{array}$ \\
\hline Dependent & $\begin{array}{l}\text { 1. Childbirth } \\
\text { complications } \\
\text { among adolescents }\end{array}$ & No & $\begin{array}{l}\text { Mother has any diagnosis of a complication during labour } \\
\text { and delivery/post-delivery } \\
\text { Mother does not have any diagnosis of a complication } \\
\text { during labour and delivery/post-delivery }\end{array}$ & $16-20$ \\
\hline \multirow[t]{7}{*}{ Independent } & 1. Age & $>$ than 19 years & $\begin{array}{l}\text { When mother indicate more than } 19 \text { years at the time of } \\
\text { delivery } \\
\text { When mother indicate more than } 19 \text { years at the time of } \\
\text { delivery }\end{array}$ & 1 \\
\hline & $\begin{array}{l}\text { 2. Residential } \\
\text { area }\end{array}$ & $\begin{array}{l}\text { Rural } \\
\text { Urban }\end{array}$ & $\begin{array}{l}\text { Mother indicate code } 2 \& 3 \text { for rural } \\
\text { Motherindicate code } 1 \text { for urban area }\end{array}$ & 2 \\
\hline & 3. Marital status & $\begin{array}{l}\text { Yes } \\
\text { No }\end{array}$ & $\begin{array}{l}\text { Mothersays she is married } \\
\text { Mother deny being married }\end{array}$ & 3 \\
\hline & $\begin{array}{l}\text { 4. Level of } \\
\text { education }\end{array}$ & Illiterate & $\begin{array}{l}\text { Motherindicates completion of secondary/college or } \\
\text { tertiary qualification at time of delivery for adolescent } \\
\text { Motherdoes not consent to having completed primary, } \\
\text { secondary/college/tertiary qualification on never entered } \\
\text { school at time of delivery for adolescents }\end{array}$ & $5-6$ \\
\hline & 5. Antenatal Care & $\begin{array}{l}\text { Yes } \\
\text { No }\end{array}$ & $\begin{array}{l}\text { If mother has } 2,3 \text { visits or more } \\
\text { If a mother had } \\
\text { No visit or one }\end{array}$ & $7,8,10-13$ \\
\hline & 6. Parity & $\begin{array}{l}1 \\
2\end{array}$ & $\begin{array}{l}\text { Mother indicate one } \\
\text { Mother indicate more than two }\end{array}$ & 9 \\
\hline & 7. Co-morbidities & Yes & $\begin{array}{l}\text { When obstetric condition occur with other co-morbidities } \\
\text { during intra-partum or post-partum are noted on } \\
\text { admission to the labour ward, during labour and at } \\
\text { the time of delivery or there after } \\
\text { When obstetric condition does not occur with } \\
\text { co-morbidities on admission to labour ward, during } \\
\text { intrapartum or post-partum, at the time of } \\
\text { delivery and after delivery }\end{array}$ & 27 \\
\hline
\end{tabular}


followed by prolonged labour at $42 \%$ (21), postpartum hemorrhage (PPH) at $20 \%$ and Pre rupture of membrane (PROM) was at 16\% (8) (See Figure 7(b)). Figure 3 showed a total of 50 patients with complications on admission. Out of those, 21 (42\%), reported having had prolonged labour, 10 (20\%) Pre rupture of membranes (PROM), 6 (12\%) preterm labour, 4 (8\%) Placenta Previa, 2 (4\%) severe eclampsia) and 7 (14\%) reported various complications classified under "others".

Figure 4 shows 59 (44.0\%) of adolescents labour lasting more than 18 hours. Please note: four patients came fully dilated and delivered upon admission. While Figure 5 indicates that of the 62 respondents who developed complications after admission (intrapartum period), 37 (59.7\%) reported developing Cephalo-pelvic disproportion, and 13 (21.0\%), prolonged labour, 5 (8.1\%) had Ante Partum Hemorrhage (APH), 7 (11.2\%) had "other" complications which included cord prolapse $1(1.6 \%)$, Fetal distress 2 (3.2\%), while compound presentation, failed induction, maternal distress and preterm labour/PROM each had $1(1.6 \%)$ respectively.

Figure 6 show results of the causes of complications after admission, "Big baby" was cited by 23 (46.0\%) of respondent and 19 (38.0\%) cited other complications such as $\mathrm{APH}$, cord prolapse, fetal distress, mal-presentation/position,

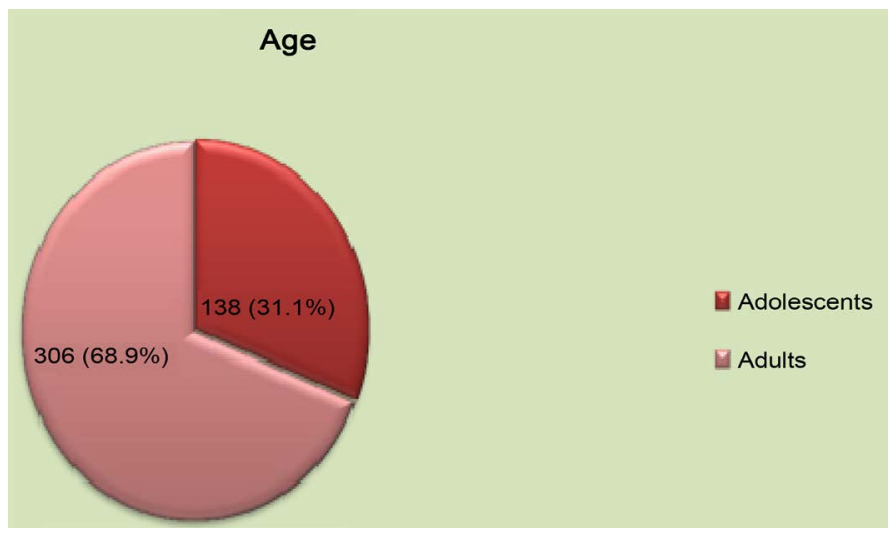

Figure 2. Adolescent mothers' age prevalence $(n=138)$.

COMPLICATIONSON ADMISSION

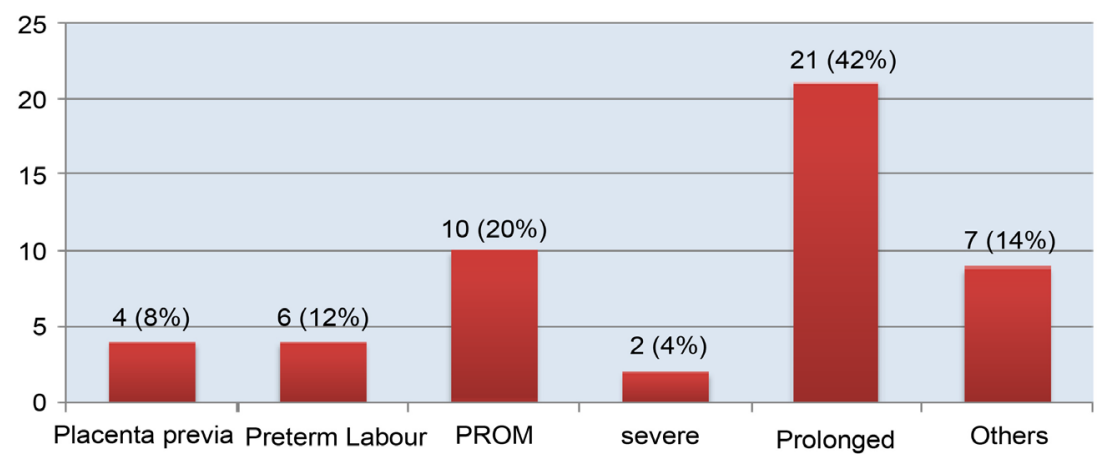

Figure 3. Complications on admission-adolescents $(n=50)$. 


\section{DURATION OF LABOUR}

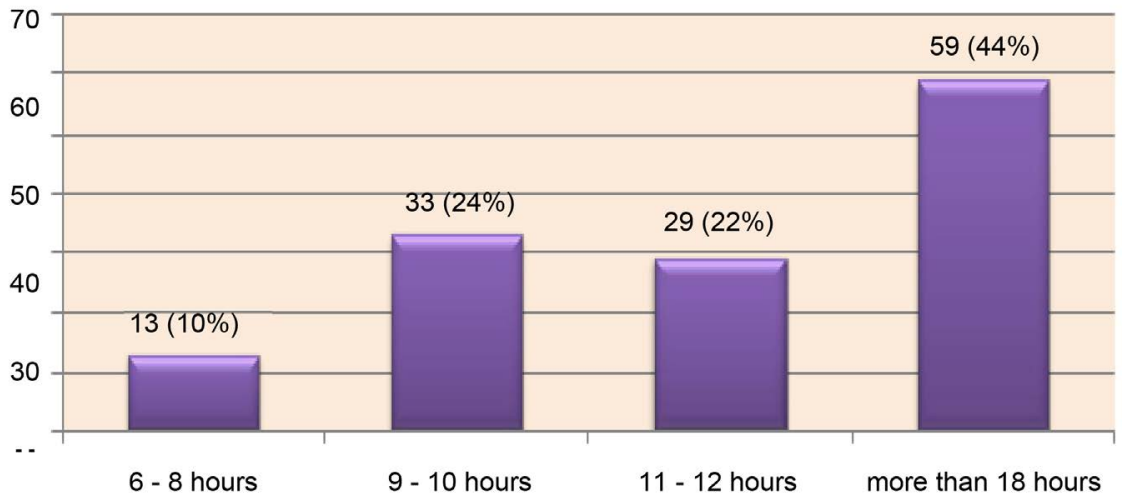

Figure 4. Duration of labour.

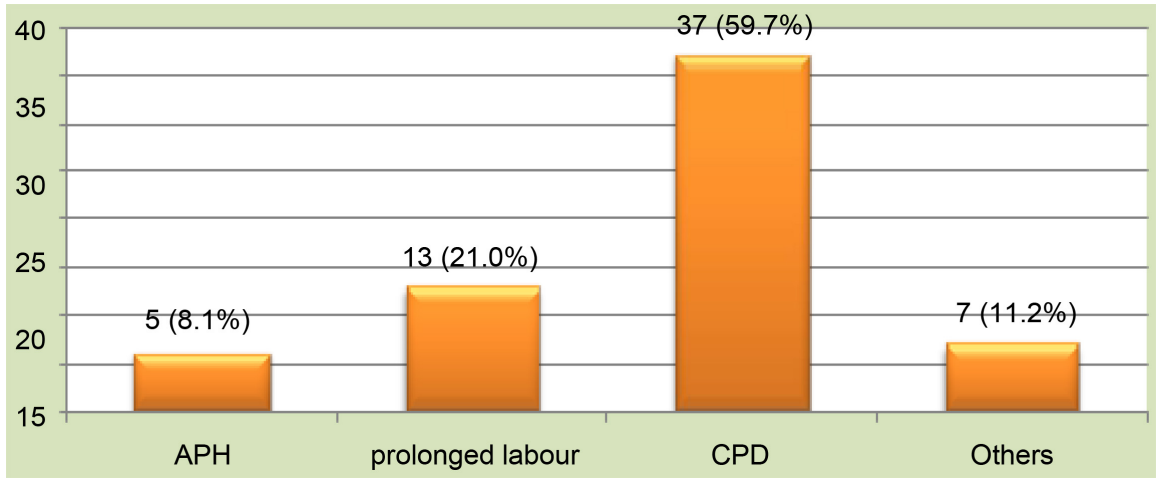

Figure 5. Complications intrapartum.

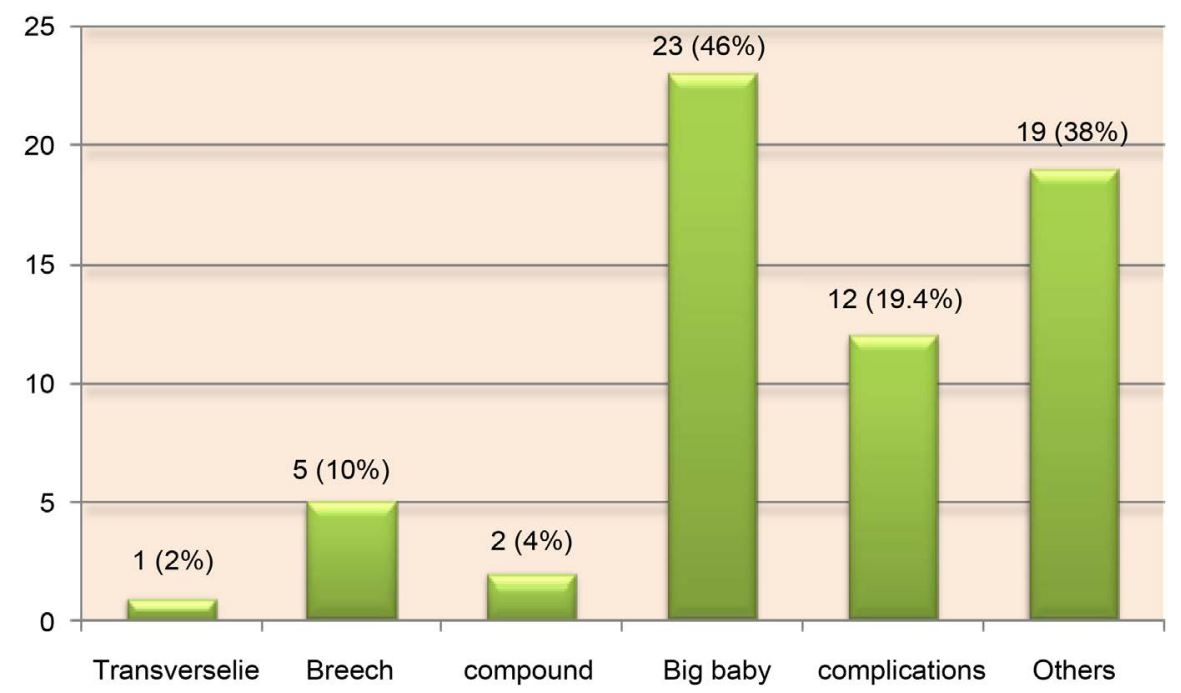

Figure 6. Causes of complication after admission $(n=62)$.

physiological CPD, prolonged 1st stage of labour and PROM.

Figure 7(a) shows that $2(20 \%)$ developed PPH which was due to atonic uterus and $60 \%$ had developed various complications ranging from unidentified 
cause, perineal tears to a spontaneous episiotomy.

Figure 7(b) shows results of the most common complications namely; Cephalo-pelvic disproportion (CPD) which accounted for 59.7\% (37), followed by prolonged labour-42\% (21), Postpartum.

Hemorrhage $(\mathrm{PPH})-20 \%$ (2), Pre rupture of membranes (PROM) $-20 \%$ (10).

Figure 8 shows that $51.4 \%$ of deliveries were spontaneous vaginal deliveries (SVD), 39.9\% were Caesarean section. Figure 9 shows that 88 (63.8\%) partographs were opened from the General Hospital, 29 (21\%) of the adolescents did not come with a partograph and $10(7.2 \%)$ were opened at the district hospital while 4 (2.9\%) were opened at the clinic/health Centre.

\subsection{Socio-Demographic Characteristics and Age Prevalence Associated with Childbirth Complications in Adolescent Mothers}

Table 3 shows that majority 125 (90.6\%) of the respondents were aged between 17 and 19 years. In terms of a residential area, majority of the respondents 112

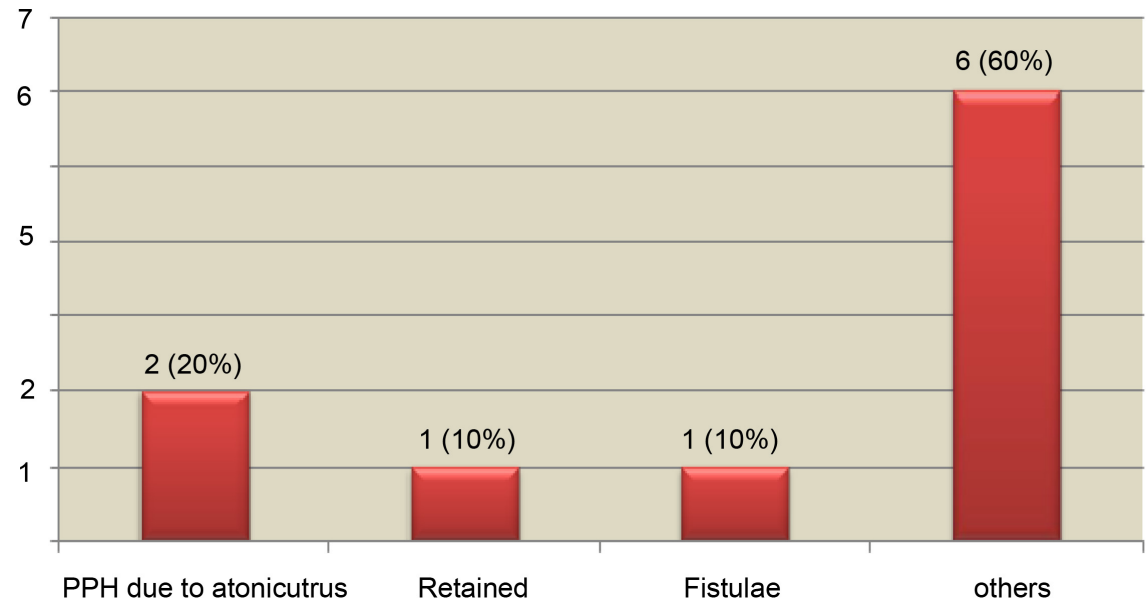

(a)

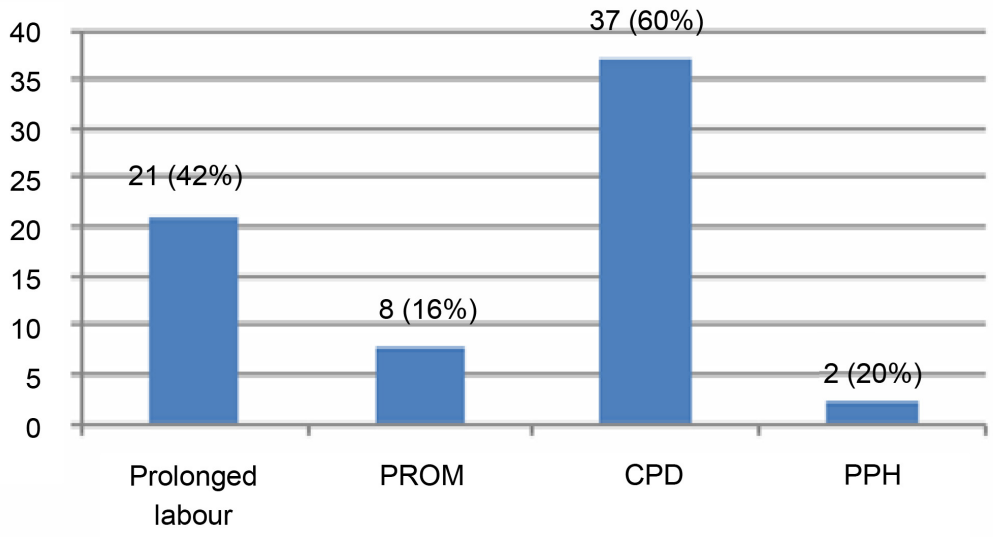

(b)

Figure 7. (a) Post-partum complications that led to PP. (b) Childbirth complications. 


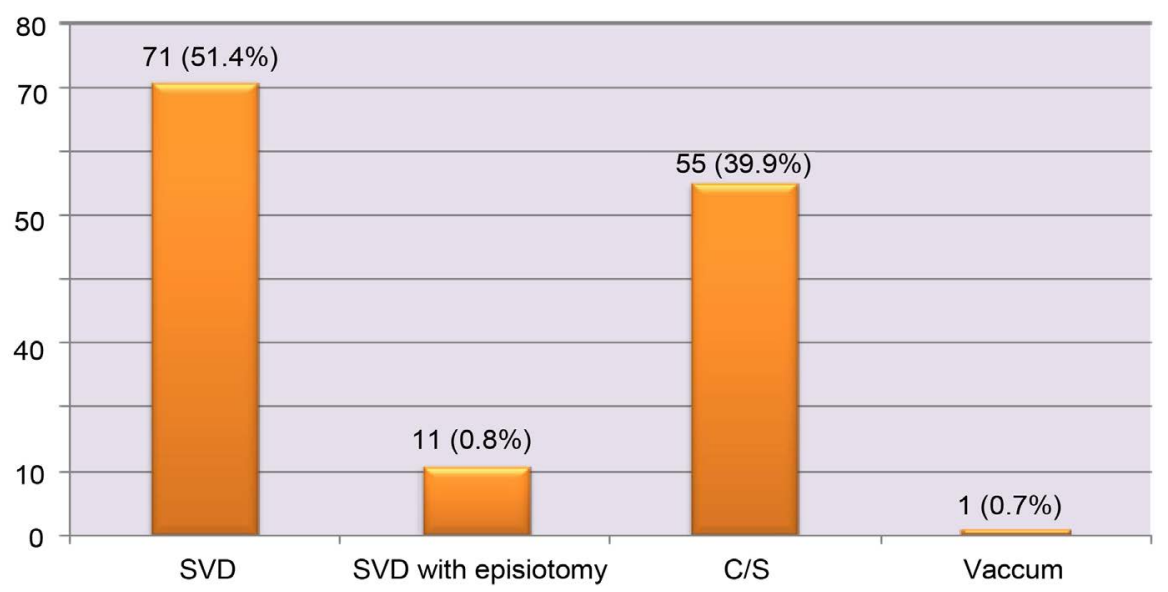

Figure 8. Interventions to assist in the delivery.

Table 3. Frequency distributions of demographic characteristics of patients $(n=138)$.

\begin{tabular}{|c|c|c|c|}
\hline \multicolumn{2}{|c|}{ Variable } & \multirow{2}{*}{$\begin{array}{c}\text { Frequency } \\
13\end{array}$} & \multirow{2}{*}{$\begin{array}{c}\text { Percent (\%) } \\
9.4\end{array}$} \\
\hline & Less than 17 years & & \\
\hline $\begin{array}{l}\text { Age at delivery } \\
\text { time }\end{array}$ & 17 - 19 years & 125 & 90.6 \\
\hline \multirow{5}{*}{ Residential area } & Total & 138 & 100.0 \\
\hline & Rural & 112 & 81.1 \\
\hline & Urban & 25 & 18.1 \\
\hline & Tanzania & 1 & 0.7 \\
\hline & Total & 138 & 100.0 \\
\hline \multirow{3}{*}{ Marital Status } & Married & 98 & 71.0 \\
\hline & Single & 40 & 29.0 \\
\hline & Total & 138 & 100.0 \\
\hline \multirow{4}{*}{$\begin{array}{l}\text { Highest level of } \\
\text { education }\end{array}$} & None & 4 & 2.9 \\
\hline & Primary & 78 & 56.5 \\
\hline & Secondary & 56 & 40.6 \\
\hline & Total & 138 & 100.0 \\
\hline \multirow{4}{*}{ Parity } & Nil & 46 & 33.3 \\
\hline & One & 84 & 60.9 \\
\hline & Two-three & 8 & 5.8 \\
\hline & Total & 138 & 100.0 \\
\hline \multirow{4}{*}{$\begin{array}{l}\text { No. of ante natal } \\
\text { visits }\end{array}$} & None & 1 & 0.7 \\
\hline & One-four & 114 & 82.6 \\
\hline & More than 4 visits & 23 & 16.7 \\
\hline & Total & 138 & 100.0 \\
\hline \multirow{4}{*}{$\begin{array}{c}\text { Where ANC was } \\
\text { done }\end{array}$} & Health centre/centre & 49 & 35.8 \\
\hline & Clinic static/mobile & 88 & 64.2 \\
\hline & No ANC & 1 & 0.7 \\
\hline & Total & 138 & 100.0 \\
\hline
\end{tabular}




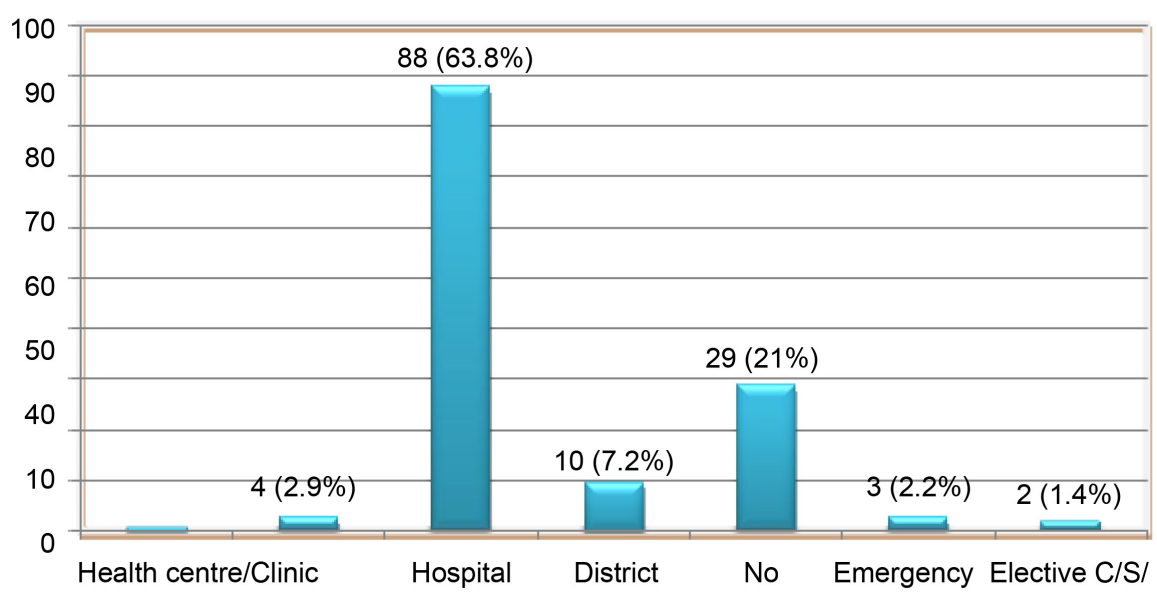

Figure 9. Place where partograph was opened to monitor progress of labour $(n=138)$.

(81.1\%) were based in rural areas of Mbala, Mpulungu and Senga, while 25 (18.1\%) were based in the urban area of Mbala and $1(0.7 \%)$ came from Tanzania. Most of the respondents 98 (71\%) were married and 40 (29.0\%) were single. The findings on the respondents highest level of education shows that more than half $82(59.4 \%)$ of the respondents had either attained primary or no level of education at all, (40.6\%) had attained secondary education. Ninety one 91 (65.9\%) of the respondents reported 3 to 4 ante natal visits with only $1(0.7 \%)$ of the respondents reported undertaking no ante natal visit. Most of the respondents 77 (56.2\%) reported attending ANC from static clinics (21.9\%) from health centers, $19(13.9 \%)$ health posts and $11(8.0 \%)$ mobile clinics.

Table 4 (four) shows that most of the respondents 5 (55.6\%) had Anemia and $3(33.3 \%)$ had Malaria.

\subsection{Cross Tabulation between Dependent and Independent Variables}

Table 5 shows the cross tabulations between the dependent and the independent variables to test for statistical significant association. The results indicates that there is a statistically significant association observed between childbirth complications and parity $\left(\mathrm{X}^{2}=10.410, \mathrm{p}=0.001,2\right.$-tailed $)$. A higher rate of adolescent mothers with parity of one (58.5\%) had childbirth complications as compared to those with parity of two or more whose rate stood at $0 \%$.

However, there were no statistically significant associations between childbirth complications and age. $\left(\mathrm{X}^{2}=0.009, \mathrm{p}=0.926,2\right.$-tailed $)$, area $\left(\mathrm{X}^{2}=0.032, \mathrm{p}\right.$ $=0.858,2$-tailed $)$ marital status $\left(\mathrm{X}^{2}=0.151, \mathrm{p}=0.698,2\right.$-tailed $)$, Level of residential education $\left(\mathrm{X}^{2}=1.792, \mathrm{p}=0.181,2\right.$-tailed $)$, number of ante natal visits $\left(\mathrm{X}^{2}\right.$ $=1.578, \mathrm{p}=0.209,2$-tailed $)$ and co-morbidities $\left(\mathrm{X}^{2}=2.006, \mathrm{p}=0.157,2\right.$-tailed $)$.

Table 6 show results of binary logistic regression a test which was done to check or the combined impact of the independent variables on childbirth complications (dependent variable). With all cases included in the analysis, the dependent and independent variables were coded as shown in Table 6. It was 
Table 4. Co-Morbidities associated with childbirth complications among adolescents $(n=9)$.

\begin{tabular}{cccc}
\hline & Variable & Frequency & Percent (\%) \\
\hline \multirow{2}{*}{$\begin{array}{c}\text { Comorbidity } \\
\text { among the }\end{array}$} & Malaria & 3 & 33.3 \\
respondents & Anemia & 5 & 55.6 \\
& Others & 1 & 11.1 \\
& Total & 9 & 100.0 \\
\hline
\end{tabular}

Table 5. Associations between dependent and independent variables.

\begin{tabular}{|c|c|c|c|c|c|c|}
\hline \multicolumn{2}{|c|}{ Variable } & \multicolumn{2}{|c|}{$\begin{array}{l}\text { Childbirth } \\
\text { complications }\end{array}$} & \multirow[t]{2}{*}{ Total } & \multirow{2}{*}{$\begin{array}{l}\text { Chi-Square } \\
\text { Value }\end{array}$} & \multirow[t]{2}{*}{ p-value } \\
\hline & & No & Yes & & & \\
\hline \multirow{2}{*}{$\begin{array}{l}\text { Age at time } \\
\text { of delivery }\end{array}$} & $<17$ Years & (6) $46.2 \%$ & (7) $53.8 \%$ & (13) $100.0 \%$ & \multirow{2}{*}{0.009} & \multirow{2}{*}{0.926} \\
\hline & 17 - 19 years & (56) $44.8 \%$ & (69) $55.2 \%$ & (125) $100.0 \%$ & & \\
\hline \multirow{2}{*}{$\begin{array}{l}\text { Residential } \\
\text { area }\end{array}$} & Rural & (49) $44.5 \%$ & (61) $55.5 \%$ & (110) $100.0 \%$ & \multirow{2}{*}{0.032} & \multirow{2}{*}{0.858} \\
\hline & Urban & (13) $46.4 \%$ & (15) $53.6 \%$ & (28) $100.0 \%$ & & \\
\hline \multirow[b]{2}{*}{ Marital Status } & Married & (43) $43.9 \%$ & (55) $56.1 \%$ & (98) $100.0 \%$ & \multirow[b]{2}{*}{0.151} & \multirow[b]{2}{*}{0.698} \\
\hline & Not married & (19) $47.5 \%$ & (21) $52.5 \%$ & (40) $100.0 \%$ & & \\
\hline \multirow{2}{*}{$\begin{array}{c}\text { Level of } \\
\text { education }\end{array}$} & Illiterate & (33) $40.2 \%$ & (49) $59.8 \%$ & (82) $100.0 \%$ & \multirow{2}{*}{1.792} & \multirow{2}{*}{0.181} \\
\hline & Literate & (29) $51.8 \%$ & (27) $48.2 \%$ & (56) $100.0 \%$ & & \\
\hline \multirow{2}{*}{ Parity } & One & (54) $41.5 \%$ & (76) $58.5 \%$ & (130) $100.0 \%$ & \multirow{2}{*}{10.41} & \multirow{2}{*}{0.001} \\
\hline & $>2$ & (8) $100.0 \%$ & $0.0 \%$ & (8) $100.0 \%$ & & \\
\hline \multirow{2}{*}{$\begin{array}{l}\text { No. of ante } \\
\text { natal visits }\end{array}$} & 2 or less & (8) $33.3 \%$ & (16) $66.7 \%$ & (24) $100.0 \%$ & \multirow{2}{*}{1.578} & \multirow{2}{*}{0.209} \\
\hline & $>2$ & (54) $47.4 \%$ & (60) $52.6 \%$ & (114) $100.0 \%$ & & \\
\hline \multirow{2}{*}{ Co-morbidities } & No & (60) $46.5 \%$ & (69) $53.5 \%$ & $100.0 \%$ & \multirow{2}{*}{2.006} & \multirow{2}{*}{0.157} \\
\hline & Yes & (2) $22.2 \%$ & (7) $77.8 \%$ & (9) $100.0 \%$ & & \\
\hline
\end{tabular}

Table 6. Binary logistic regression to test the impact of the independent variables against the dependent variable.

\begin{tabular}{cccccc}
\hline \multirow{2}{*}{ Variable Level } & P-value & Odds Ratio & \multicolumn{2}{c}{ 95\% C.I } \\
\cline { 5 - 6 } & & & Lower & Upper \\
\hline Delivery Age (1) & 0.33 & 0.594 & 0.208 & 1.694 \\
Place (1) & 0.94 & 1.042 & 0.359 & 3.02 \\
Marital Status (1) & 0.686 & 0.822 & 0.318 & 2.126 \\
& Literacy (1) & 0.169 & 0.544 & 0.228 & 1.297 \\
& ANC (1) & 0.335 & 0.556 & 0.168 & 1.837 \\
& Co-morbidities (1) & 0.562 & 1.769 & 0.257 & 12.155 \\
Parity (1) & 0.001 & 0.061 & 0.022 & 0.168 \\
Constant & 0.001 & 10.579 & &
\end{tabular}

Binary logistic regression (Variable(s) entered on step 1: delivery Age, Place, M. Status, Level of education, ANC, co-morbidities, Parity). 
observed that, from the table of variables not in the equation, changes in parity from one or less to two or more would contribute significantly to the regression model while changes in all other variables would not contribute significantly.

In addition, the regression model was statistically significant $\left(\mathrm{X}^{2}=26.790, \mathrm{p}=\right.$ 0.000 ) and could account for $39.7 \%$ variation in the outcome variable, making it a weak model. The model could predict the presence of childbirth complication with an accuracy of $85.5 \%$ and the absence of childbirth complications with $67.7 \%$ accuracy. Overall, the model had a prediction accuracy of $77.5 \%$.

Therefore, in the model or equation, changes in parity from one or less to two or more impacted significantly on the model, with a p-value of 0.001 . Changes in all other variable levels were not statistically significant to the model, with $\mathrm{p}$-values ranging from 0.169 to 0.94 . Changes in parity from one or less to two or more reduced the odds of suffering childbirth complications to 0.061 times.

\section{Discussion of the Findings}

\subsection{Introduction}

This chapter discusses findings of the study according to the objectives which were set as follows: 1) to identify childbirth complications among adolescents who gave birth at Mbala General Hospital 2) to determine Socio-Demographic characteristics associated with childbirth complications in adolescent mothers who gave birth at Mbala General Hospital. 3) to determine co-morbidities associated with childbirth complications among adolescents who gave birth at Mbala General Hospital.

\subsection{Childbirth Complications among Adolescent Mothers}

Childbirth, although considered a normal physiological process, oftentimes complications occur [1] which may lead to mortalities and morbidities especially in adolescents aged $10-19$ years [3]. This study showed that more than half of 138 (58.6\%) adolescent mothers developed complications such as Cephalo-pelvic disproportion $(\mathrm{CPD})$, prolonged labour, postpartum hemorrhage ( $\mathrm{PPH}$ ) and pre-rupture of membranes (PROM) (Figure 7(b)) and this was similar to [49]; whose study results revealed complications such as CPD, eclampsia, prolonged labour, hemorrhage and caesarean section as well as low birth weight and preterm delivery. However, there were differences in Mores results where eclampsia, low birth weight and preterm labour were also observed. This could have been due to different age groups studied as in her study the participants were less than 16 years old. Hence, CPD, prolonged labour and PPH were experienced by the participants in both studies. This could have been due to young maternal age which exposes them to complications of labour and delivery. Therefore, interventions such as caesarian sections were performed in $39.9 \%$ adolescent mothers (Figure 8). This was necessitated by availability of EmoC services at the institution as a referral centre, made possible by good government health policy 
to bring health as closer to the people as possible [77]. Since some of the adolescent mothers could not deliver vaginally, Caesarian section was made possible for the adolescent mothers who were referred from the peripheral health centre. According to [18] he describes the effective referral system and caesarian section as the best strategies to reduce morbidity from occurring [6] [7].

The current study and Moraes' study were in conformity because both studies were conducted in the rural areas where practices such as giving of young girls in marriage at a tender age as soon as they drop out of school [17] may be similar. Furthermore, drawing from the two study results, it can be partially concluded that young maternal age of less than 19 years was at risk of complications which ranged from physical to physiological effects. Hence, being aware of such complications in adolescents will facilitate positive initiative to strategize interventions to mitigate impact of complications on young mothers in order to have a productive nation and a healthy people in the district.

In this study, $12 \%$ of adolescent mothers came with spontaneous preterm labour. This finding was in conformity with [43]; who found $15 \%$ of the adolescent mothers to have had preterm labour. This could have been attributed to bodily immaturity resulting from underlying biological factors such as Gynaecological immaturity and incomplete pelvic growth as reported by studies in [46]; Chadwick and Foster 2013 in [9], [45] that could have caused preterm labour among adolescents in this age group. Preterm labour and delivery had negative effects on service delivery which lead to long stay in the hospital. It increased demand on institutional costs resulting in creating a deficit on other services in the institution. In this study, preterm labour could not be a very serious factor in physiological and economical terms compared to prolonged labour whose per cent was high (42\%), suggesting that it had potentially predisposed adolescent mothers to infections. However, the adolescent mothers in this study did not show any signs of infection at least in the first six hours post-delivery and during labour. This could have been attributed to implementation of good health policies and guidelines for EmOc services at the institution which included giving antibiotics to woman in labour with pre-rupture of membranes (PROM) for more than six (6) hours and those who had prolonged labour, to prevent and combat infections as chances of developing infection related to complication such as Chorioamnionitis and endometriosis were possible as most adolescents labored for more than 18 hours (Figure 4).

Prolonged labour may cause maternal distress as a result of exhaustion catalyzed by energy depletion and accumulation of lactic acid which later affects physiological function; through a series of chain responses that affect the uterus through release of norepinephrine, prolonged epinephrine secretion causes a rebound effect leading to initial inhibition of uterine contractility [78]. In this study, prolonged labour could have resulted from cephalo-pelvic disproportion (CPD) (Figure 5) resulting in caesarean section to reduce maternal or fetal morbidities (Figure 8). This is consistent with [4] whose findings revealed obstructed 
labour as one of the leading causes of complications of childbirth among women aged between 15 and 19 years in Sub-Saharan Africa and Southeast Asia. Prolonged labour emanates from CPD, a result of failure of the feotal head to pass through the maternal pelvis which at sometimes is malformed for example (plate-peloid), or due to big baby or other factors. This was similar to [79] who reported high rates of cephalo-pelvic disproportion and caesarean section rates. It may therefore entail that CPD may be considered a risk for complications in adolescents and should be identified early during the antenatal period for possible elective caesarian section to prevent exposing adolescent mothers to painful labour processes thereby reducing the odds of suffering complications.

Therefore, there is a need for institutions in the district to strengthen antenatal assessments of the pelvis and physical assessment to mother admitted to the labour ward to detect CPD early and put up appropriate interventions. The sources of such complications are early marriage and teenage pregnancies which should be avoided at all costs by considering appropriate and effective strategies for dissemination of information, for example, information, education and communication (IEC) as the first and best preventive measure. In the case of those who cannot abstain, it may be necessary to encourage the use condoms to prevent pregnancy and avoid consequences of health problems emanating from complications of childbirth [12] in tens of millions of adolescent mothers.

Similarly, a study by [40] reported use of instrumental delivery (forceps and caesarean) although the study revealed a high proportion of vaginal deliveries which was attributed to smaller babies contrary to the current study, whose baby weights ranged from more than 2.500 grams to more than 3.500 grams. Delivery of small babies by SVD could have been influenced by other factors (co-morbidities) such as Anemia, gestational diabetes or hypertensive disorders. However, big babies noted in the current study could be attributed to good government policies in programs like 1000 critical days which emphasizes good nutrition throughout pregnancy and lactation period, supplementation of micro nutrients and advocacy for abolishing bad cultural practices of not eating foods rich in proteins, for example eggs; a source protein which a mother can afford during pregnancy.

The postpartum complications among the adolescent mothers showed PostPartum Hemorrhage (PPH) from different causes such as atonic uterus (Figure 7), perineal tear, and retained products of conception. These findings were in tandem with a study by [80], [42] of the United States who reported greater odds for post-partum hemorrhage, poor fetal growth and fetal distress in the $15-19$ year-olds. PPH is one of the five (5) major causes of maternal mortality worldwide [6]. It may continue to claim lives of mothers if not eliminated by serious practical interventions such as effective management of third $\left(3^{\text {rd }}\right)$ stage of labour with oxytocics upon delivery of the anterior shoulder of the fetus, complete delivery of the placenta and membranes, suturing of perineal tears, bi-manual compression of the uterus to occlude bleeding and proper monitoring of post-de- 
livery vital signs especially blood pressure. Therefore, Midwives being professionals mandated with the responsibility of caring and assisting mothers in labour, more especially this vulnerable group of adolescents, health care providers must seriously abide by guidelines in the management of the third stage of labour to prevent such complications and loss of lives.

Post-delivery vital signs readings are recorded on the partograph as recommended by the guidelines. In this study, a partograph being an important tool used in each and every labour ward to assist health personnel monitor progress of labour to detect any deviations from normal and or complications that may arise during labour was checked from each file to see if at all some complications were recorded so that these could be captured as a source of information pointing to some complications. Its usage was more at the General Hospital than lower facilities (see Figure 9). In this regard, some complications could have been identified earlier at lower facilities and could have reduced the adolescent mothers' period of suffering by referring them early enough. The none utilization of partograph by lower facilities could have been attributed to a shortage of personnel in these facilities or to attitude towards work (laziness); and or administrative factors such as inadequate funds to sustain the noble activity of procuring logistics that support service delivery to mitigate morbidity and mortality rates for mothers in reproductive age (adolescent mothers).

\subsection{Socio-Demographic Characteristics Associated with Common Childbirth Complications}

Socio-demographic characteristics in this study included age, residential area and marital status, level of education, parity and number of antenatal visits. Almost all the 138 adolescents in the study were above 17 years (Table 3 and Figure 2), translating into $31.1 \%$ age prevalence falling between $17-19$ years. According to [13], Zambia has been graded fifth in adolescent birth rate in the region and 35\% of these young rural girls give birth by the age of 18 years [81]. This was according to the study conducted in Zambia under (Centre for Intervention Science in Maternal \& Child Health) CISMAC. The results for this study showed Mbala district as an entity yielding such results as being on the higher side compared to the national figure which stands at $28.5 \%$ [15], [50] it stands at $30 \%$ in young women aged 15 to 19 year. These young women were said to have had either given birth or carried a pregnancy. [15] Demographic Survey reported that the percentage of adolescent pregnancy increases rapidly with age, from 5 percent among women age 15 to 59 percent among women aged 19 years. These figures are alarming and are setting a time bomb for the future if the issue is not treated with the urgency it deserves. This is an indication of the existence of early marriages in Zambia that [16] [17] had referred to as contributing to severe complications of childbirth among adolescent mother which may lead to morbidities such as unsafe abortion and others as already alluded to in 5.2 above. This is in tandem with [21] who found that early pregnancies were known to con- 
tribute to severe childbirth complications in adolescents as young maternal age was a predisposing factor. This may imply that young maternal age is a risk to childbirth complications in Mbala district as the figure was higher (31.1\%) than [15] of $28.5 \%$.

The study results showed that more than three quarters of adolescents were from the rural areas, the results were in conformity with [49] [55]. The later, revealed that distance to the health facility led to failure of the adolescents to seek care and delay in doing so resulted in more than half of the adolescent mothers in his study dying in South Africa alone. However, in the current study, no maternal death occurred during the study period probably owing to the availability of the effective referral system and EmoC services. In other studies, such as [81], [54] in Finland, adolescents were in terms of age, in the same range. This shows that adolescent birthing age is a worldwide social problem [4] which cuts across nations. This can be attributed to factors such as globalization, use of socio media and exposure to television which eventually corrupt adolescents' minds who would want to experiment what they saw on the media and end up falling pregnant, hence, being at risk for a complication of childbirth. This is why in our African culture children never used to know much about sex and reproduction information until they attained menarche; when grandparents and aunties would start educating them gradually about reproductive matters. However, policies such as children's rights on reproductive health and sexual education which starts as early as grade five when some children are about seven years old have been put in place. Exposure to use of phones where such information can be accessed easily is also on the increase, thereby, predisposing children to risky behaviors that result in unwanted pregnancies and eventually risks of childbirth complications.

However, human beings relate to one another even in terms of reproduction. Marital status was another socio-demographic characteristic this study considered to be a factor in contributing to childbirth complication in adolescents. About $75 \%$ of the adolescent mothers recruited in the study were married. The results were in conformity with studies by [61], [81] that looked at Management of Pregnancy and Childbirth among Adolescents. The results showed that more than half of the adolescents were married. This could be as a result of parents giving adolescents in marriage soon after reaching menarche or drop out of school [17] Although not all adolescents in developing countries are married off early, it is important to note that childbearing in adolescents risks complication of labour and delivery as discussed in the literature above [41] p 13 in the dissertation. Contrary to this, other studies conducted both in developed and developing countries could not agree that the relationship between age and birth complications in adolescent mothers occur as a result of physiological immaturity. For example, results of the study by [36] did not clearly show whether poor birth outcomes of those pregnancies were related to the biological immaturity leading to adverse birth outcomes. However, in this study, we cannot affirm that 
age can be ruled out completely as some adolescents delivered without complications by spontaneous vaginal delivery (SVD) [40] while others did develop complications [46] [47]. This could be a multifaceted factor which needs further research to explore the phenomenon.

The study results on level of education revealed that almost all adolescent mothers had attained either primary or secondary education although more than half only went up to primary school level. Studies by [6] [40] [63], report on adolescent pregnancy, linked low education levels with early childbearing in adolescent girls between 15 to 19 years. This seems to suggest that illiteracy or low levels of education may predispose to early pregnancy and therefore childbirth complications. This may be as a result of difficulties in comprehending the consequences of early childbearing as opposed to late childbearing. On the contrary, in this study, almost half of the adolescents had attained a secondary level of education and among these, some had complications related to childbirth. Nevertheless, this does not mean that those dangers cannot be simplified to a level where adolescent mothers can get the concepts of the consequences of early childbearing as an adolescent. The attainment of secondary school education in some adolescents in the study can be attributed to good Zambian educational policies such as Re-entry Policy which promote the girl child to continue with school after delivery as a way of reducing illiteracy. Re-entry policy is beneficial as it enables the girl child to be more educated, able to comprehend health information, thereby improving health for adolescents to reduce the risk of childbirth complications.

Parity is the number of children a woman may have had prior to the current pregnancy. In this study, mothers who had given birth once and those that were carrying the pregnancy for the first time (nullipara) suffered childbirth complications more than those who had two or more. It meant that those who had given birth for the second or third time did not suffer complications of childbirth as compared to those who delivered for the first time. The results were in line with [18] whose study reported primigravidas (parity nil) women being 12 times more likely $(\mathrm{OR}=11.89,95 \% \mathrm{CI}, 1.153 ; 122.693)$ to have a complication during labour and delivery. Reference "[70]" of the USA, findings could be in support of the above, for he found emergency Caesarean Section as one significant adverse outcome among younger mothers. This means that young maternal age coupled with parity of less than two may be related to childbirth complications. Therefore, the likelihood of parity being associated with complications of childbirth was high.

Results on antenatal visits in this study were similar to results by [64] in Sri Lanka which showed that prenatal care helps to decrease adverse pregnancy outcomes for adolescent pregnant women by reducing risk factors through education and social support. This is because the more mothers were in contact with the health personnel during antenatal, the more chances they had to be adequately screened for possible ailments that could compromise labour and deli- 
very. [66] [67] findings showed that Antenatal care (ANC) services helped to reduce maternal mortality and also helped in achieving optimal health outcomes for the mother through screening. Furthermore, a study by [56] that looked at Maternal and Child Health among the urban poor in Kenya revealed an increase in distance to the nearest healthcare facilities being associated with fewer antenatal visits. In the current study, (99.3\%) had a minimum of one (1) to a maximum of four (4) visits or more (Table 3). This means adolescent mothers had good opportunities for check-ups and intervention to correct ailments or abnormalities that would have been sources of risks for complications of childbirth. However, we could still ask the question why some adolescent mothers developed complications with $99.3 \%$ antenatal coverage. This could be attributed to a number of factors from both health workers and adolescents; ranging from quality of work, lack of facilities to use, inadequate health care providers and lack of logistics. Therefore, there is a need for further research on the phenomenon to come up with a solution.

In Zimbabwe, however, a study by [47] noted a weak relationship between pregnancy and knowledge of complication of pregnancy among adolescent mothers but somehow corresponded to late booking. In this study, most of the adolescent mothers were booked for screening after the first trimester defeating the purpose of early booking. Early booking entails detection of co-morbidities that may compromise pregnancy, labour and delivery. This lack of knowledge may be the reason why the adolescents in this study could not book early. Hence, the consequences of complications of labour and delivery occurred in $58.6 \%$ of the adolescents. According to [68], late booking for antenatal care makes the pregnant adolescents miss out health interventions that are recommended. These interventions such as early booking can help in reducing maternal mortality and in achieving optimal health outcomes for the mother [66]. This could explain why there were more than half of adolescents with complications in this study. A study by [69] linked lack of access to prenatal care as a socioeconomic factor. In this study, prenatal care, however, could be equated to a social factor as government policies have taken health closer to the people as evidenced by presence of Health posts, health centre, clinics throughout the district; and Emoc services are provided by hospitals found in all district [79].

\subsection{Co-Morbidities Associated with Childbirth Complications}

To establishing co-morbidities associated with childbirth complications that could compromise the health of the adolescent mother while in labour or influence occurrence of complication, these co-morbidities included anemia, malaria and severe vaginal warts (Table 4). The results were consistent with [71] [73], [6] who found anemia, eclampsia; proteinuria, UTI and pyelonephritis being significant risk factors. According to [73] the adolescent mothers were at risk of developing Anemia which he found to be the most common medical disorder among adolescent mothers at delivery. This could be attributed to the double 
impact for Iron (hemoglobin) demand by the fetus growing in the uterus of the adolescent; and nutritional needs during the peak time of adolescence by the young mothers' body to prepare adequately for reproduction. Therefore, Information Education and Communication (IEC) on negative impacts of early pregnancy on labour and delivery complications need to be intensified in schools and in all places where adolescents are found to reduce on morbidities related to childbirth complications and contribute to SDG number three which advocates for health for all at all ages. On the other hand, this study found malaria and Anemia to be the most prominent comorbidities observed. These findings were similar with [6] that recorded Human Immunodefiencey Virus (HIV), Malaria and Sexually Transmitted Infections (STI) as conditions that can influence health status of the young mother. However, the co-morbidities in the study did not yield any statistical significance and could not be considered a risk factor.

\subsection{Cross Tabulation between Dependent and Independent Variables}

This was done to test for statistical significance between childbirth complications and other variables (age, residential area, and marital status, level of education and antenatal visits). Results showed a statistically significant association between childbirth complications and parity $\left(\mathrm{X}^{2}=10.410, \mathrm{p}=0.001,2\right.$-tailed $)$. This means a higher rate of adolescent mothers with parity of one (58.5\%) had childbirth complications as compared to those with parity of two or more whose rate stood at $0 \%$; Refer to (Table 5) which showed a positive association between the respondents' parity and childbirth complications. The results for cross tabulation showed an increase in those with no complications and those with parity of one. Subsequently, there was a drastic decrease of zero per cent complication in those with two or more children. This implies that null-para adolescents are prone to childbirth complications than multiparous adolescents. The observed trend was statistically significant as the Chi-square test yielded a p-value of 0.001 , which is less than the threshold of 0.05 . Hence, we reject the null hypothesis and conclude that there is an association between parity and childbirth complications among adolescents $\left(\mathrm{X}^{2}=10.410, \mathrm{~N}=138, \mathrm{p}=0.001,2\right.$-tailed $)$.

With regard to other variables and childbirth complications, there were no statistically significant associations. On the other hand, the current study did show that age influenced childbirth complications when cross tabulation was done. The results showed an increase of complications in both categories of below 17 years and the above 17 years. However, no statistically significant association was observed between age and childbirth complications from a p-value of 0.926 because it was greater than the threshold 0.05 . The evidence was not sufficient to prove the association between age and childbirth complications although the chi-square value of 0.009 showed some relations. Therefore, we conclude that there was no sufficient evidence to prove that there is an association between age and childbirth complications. This implies that other factors which 
need to be probed could contribute to complications, for example, the small stature of the mother indicates small pelvis.

In this study, some correlation between residential area, marital status, illiteracy (level of education) and childbirth complications were observed although no statistically significant association was established.

Concerning co-morbidities, the results in (Table 5 showed an increase in childbirth complication in both groups; those with no co-morbidities but developed complications; and those with co-morbidities and developed complications. However, the observed trend in this study was found not to be statistically significant as the Chi-square test yielded a p-value of 0.157 which is greater than the threshold of 0.05 . Hence, we fail to reject the null hypothesis and conclude that there was no sufficient evidence to prove that there is an association between co-morbidities and childbirth complications $\left(\mathrm{X}^{2}=2.006, \mathrm{~N}=138, \mathrm{p}>\right.$ $0.05,2$-tailed).

\subsection{Binary Logistic Regression to Test the Impact of the Independent Variables against the Dependent Variable}

Table 6 showed the binary regression test which was used to analyze the combined impact on dependent (childbirth complications) and independent variables (age, residential area, and marital status, level of education and antenatal visits as well as co-morbidities. The results showed changes in parity from one or less to two or more would contribute significantly to the regression model while changes in all other variables would not contribute significantly.

The results revealed that the regression model was significant as the Chi-square value of 26.790 , and a $\mathrm{P}$ value of 0.000 was yielded. Although the model accounted for $39.7 \%$ variation in the outcome variable, making it a weak model, it could predict the presence of childbirth complication with an accuracy of 85.5\%; and the absence of childbirth complications with $67.7 \%$ accuracy while the overall model prediction accuracy was $77.5 \%$. A p-value of 0.000 in the equation and the model implies that changes in parity from one or less to two or more would reduce the odds of suffering childbirth complications by $6.1 \%$ ( 0.061 times) $(\mathrm{OR}=$ 0.061 , CI 95\%, 0.022; 0.168). This means that adolescents with two or more children were less likely to suffer complications related to childbirth compared to those of one or no child (Nullpara). However, changes in all other variable levels were not statistically significant to the model, with $\mathrm{P}$-values ranging from 0.169 to 0.94

\subsection{Application of the Theoretical Framework to the Current Study}

The study adapted the McCarthy and Maine (1992) framework of analysis. This framework was used because it looked at how to 1) reduce the likelihood that a pregnant woman will experience serious complications of childbirth;2) improve the outcome of the woman with childbirth complications and 3) the availability of an efficient referral system to cater for EmoC services. 
The framework was suitable in the study as it looked at all the three determinants stated above and other factors such as cultural, social, economic, behavioral and biological factors in highlighting the common childbirth complications that may occur in the adolescent mother from the onset of labour through to intrapartum period and six hours postpartum.

In relation to the research findings, the framework was appropriate as it was able to bring out one component from the results, that showed that parity of two or more would reduce the odds of suffering childbirth complications in adolescents to 0.061 times $(6.1 \%)$ compared to parity of one or less. On the other hand, other socio-demographics characteristics like age, residential area, level of education, antenatal visits were not significant. But common childbirth complications were highlighted by the study such as prolonged labour, PROM, CPD and PPH. The other aspect is the presence of EmoC services at the General Hospital where the lower facilities in the district used to referrer the clients. In this regard, the theory was appropriate to the study as it guided the study process and in the formulation of the questionnaire and yielded some results.

\subsection{Limitation of the Study}

Below were the limitations of the study:

1) The study was conducted on a limited sample size $(n=138)$ hence the results may be generalized but cautiously as it only represented adolescents from one particular area of a rural setting accessing EmoC services at Mbala General Hospital.

2) The modified structured interview schedule as an observational tool could not be exhaustive in bringing out the required information; it could have had some gaps and therefore it did not get the information required. Therefore, a semi-structured questionnaire would have been more appropriate.

3) Causality could not be directly assessed as it required long term assessment and no experiment interventions were applied to the study but observations of exposure and outcome.

4) Purposive sampling method, a non-probability sampling method was used to select the study sample. Therefore; biasness could be a problem because not every adolescent mother was given the chance to participate in the study.

\subsection{Conclusion}

The objective of the study was to explore childbirth complications among adolescent mothers at Mbala General Hospital in Mbala district-Zambia. The Prevalence of maternal age was $31.1 \%$ and the study depicted parity of one to contribute significantly to childbirth complications. Childbirth complications identified by the study were Cephalo-pelvic disproportion (CPD), prolonged labour, postpartum hemorrhage (PPH), pre-rupture of membranes (PROM) and anemia for co-morbidities. It also revealed a regression model that had a statistical significance P-Value of 0.000 . The statistical significance was not observed in all the independent variables except for parity as already alluded to above. Therefore, 
there is need to build the system to reduce complications of childbirth in adolescent mothers. There is also an ongoing need to educate adolescents to avoid pregnancy by abstaining or using condoms if they cannot abstain.

\subsection{Recommendations}

Basing on the study findings, the following recommendations were made in order to reduce morbidity and mortality caused by childbirth complication in adolescent mothers:

1) All stakeholders to engage in continued sensitization of adolescents on complications of pregnancy, labour and delivery and the importance of having skilled assistances at each delivery

2) Provincial Health Office to lobby from Ministry of Health to equip facilities with already established $\mathrm{EmoC}$ centre with appropriate infrastructure and $\mathrm{Hu}$ man resources like doctors and clinical officers specialized in obstetrics.

3) The policy makers to consider separating package of care for pregnant adolescents from the combined care given to all women of childbearing mothers found in the current health care system policy, in this package a comprehensive care of psychological, social and physical care can be intensified by trained midwives (Counsellors) who will journey with these adolescent from pregnancy to post-delivery care.

4) District Health Offices to strengthen supervision of all lower facilities of care to ensure adequate adherence to set standards that will improve quality of service on adolescents and other women in childbearing age.

5) To replicate this study at a larger scale.

6) Adolescent reproductive health to been hanced.

\subsection{Strength of the Study}

The study has achieved its intended objectives. The results showed a strong association between the dependent variable (childbirth complications) and the independent variable (parity) among the socio-demographics characteristic and also identified some common childbirth complications that may occur among adolescent mothers so that appropriate interventions are done to mitigate the impact on adolescent mothers' health.

In addition, statistical methods such as chi-square test and Binary logistic regression have been applied and the results for the regression model revealed a statistical significance with $\left(X^{2}=26.790\right.$, and a $P$ value of 0.000$)$. Although the model accounted for $39.7 \%$ variation in the outcome variable, making it a weak model, but it could predict the presence of childbirth complication with an accuracy of $85.5 \%$; absence of childbirth complications with $67.7 \%$ accuracy and the overall model prediction accuracy of $77.5 \%$.

\section{Conflicts of Interest}

The authors declare no conflicts of interest regarding the publication of this paper. 


\section{References}

[1] Dippenaar, J. and Da Serra, D. (2013) Sellers' Midwifery. 2nd Edition, Lansdowne, Juta.

[2] WHO (2011) Preventing Early Pregnancy and Poor Reproductive Outcomes among Adolescents in Developing Countries. Geneva.

[3] Derme, M., Leoncini, E., Vertrano, G., Carlomgno, L. and Aleandri, V. (2013) Obstetric and Perinatal Outcomes of Teenage Pregnant Women: A Retrospective Study. Epidemiology Biostatistics and Public Health, 10, e8641.

[4] Henok, A. and Asefa, A. (2015) Prevalence of Obstructed Labor among Mothers Delivered in Mizan-Aman General Hospital, South West Ethiopia: A Retrospective Study. Journal of Women's Health Care, 4, 250.

https://doi.org/10.4172/2167-0420.1000250

[5] Cherry, A.L. and Dillon, M.E. (2014) International Handbook of Adolescent Pregnancy: Medical, Psychosocial, and Public Health Responses. Springer, Boston. https://doi.org/10.1007/978-1-4899-8026-7_21

[6] WHO (2016) Adolescent Pregnancy-Maternal, Newborn, Child and Adolescent Health.

http://www.who.int/maternal_child_adolescent/topics/maternal/adolescent_pregna ncy/en

[7] Dangal, G. (2004) An Update on Teenage Pregnancy. The Internet Journal of Gynaecology and Obstetrics, 5, 3.

[8] Shahabuddin, A.S.M., Delvaux, H., Bardají, Z., Utz, B. and De Brouwere, V. (2016) Determinants and Trends of Health Facility-Based Delivery and Caesarean Section among Married Adolescent Girls in Bangladesh. Woman and Child Health Research Centre, Department of Public Health, Institute of Tropical Medicine, Antwerpen. https://doi.org/10.1136/bmjopen-2016-012424

[9] Dunn, N. (2014) Adolescent Maternal Mortality. http://www.polis.leeds.ac.uk/assets/files/students/student-journal/Summer-2014/P OLIS-Journal-Summer-2014-Vol.11.pdf

[10] Fleming, D., Chama-Chiliba, M.C. and Koch, S.F. (2015) Utilization of Focused Antenatal Care in Zambia: Examining Individual- and Community-Level Factors Using a Multilevel Analysis. Department of Economics, University of Pretoria, Pretoria.

[11] Gyesaw, N.K. and Ankomah, A. (2013) Experiences of Pregnancy and Motherhood among Teenage Mothers in a Suburb of Accra, Ghana: A Qualitative Study. International Journal of Women's Health, 5, 773-780. https://doi.org/10.2147/IJWH.S51528

[12] Nanda, P., Mishra, A. and Mukherjee, S. (2012) A Study to Evaluate the Effectiveness of WHO Tools-Orientation Programme on Adolescent Health for Health Care Providers and Adolescent Job Aid-In Improving the Quality of Health Services Provided by Health Workers to Their Female Adolescent Clients in India. World Health Organization, Geneva.

[13] Machawira, C. (2014) School Pregnancies Call for CSOs' Big Role. Times of Zambia, 28th May 2017.

[14] Global Health (2015) Attitudes and Behaviour of Maternal Health Care Providers in Interactions with Clients: A Systematic Review.

[15] CSO (2014) Zambia Demographics Profile Index Mundi. http://www.indexmundi.com/zambia/demographics_profile.html 
[16] Kasongo, K.V. (2010) Adolescence Pregnancy-Adolescent Health and Development with a Particular Focus on Sexual and Reproductive Health. REPRONET, Lusaka.

[17] Chansa, E. (2011) Teenage Pregnancies Still a Challenge for Zambia, Provincial AIDS Co-Coordinator Advisor, and Meeting of the Provincial AIDS Task International HIV/AIDS Alliance in Zambia.

[18] Hoque, M. (2011) Incidence of Obstetric and Foetal Complications during Labor and Delivery at a Community Health Centre Midwives Obstetric Unit of Durban, South Africa. ISRN Obstetrics and Gynecology, 2011, Article ID: 259308. https://doi.org/10.5402/2011/259308

[19] Ministry of Health (2010) Adolescent Health Strategic Plan (2011-2015), Directorate of Public Health and Research, Ndeke House, Lusaka, Zambia.

[20] UNFPA and ICM (2009) Invest in Midwives and Others with Midwifery Skills to Accelerate Progress towards MDG5. http://www.internationalmidwives.org/Portals/5/UNFPA

[21] Kurth, F., Bélard, S., Mombo-Ngoma, G., Schuster, K., Adegnika, A.A., Bouyou Akotet, M.K., Kremsner, P.G. and Ramharter, M. (2010) Adolescence as Risk Factor for Adverse Pregnancy Outcome in Central Africa-A Cross-Sectional Study. PLoS ONE, 5, e14367. https://doi.org/10.1371/journal.pone.0014367

[22] WHO (2012) The Economic and Social Impacts of Maternal Death for Families in Developing Countries.

[23] CSO (2012) Zambia Demographic and Health Survey. Central Statistical Office, Ministry of Health, and ICF International, Rockville.

[24] Tawiah, E.O. (2002) Adolescent Fertility and Reproductive Health in Four Sub-Saharan African Countries. African Population Studies, 17, 31-98.

[25] CSO (2007) Ministry of Health, Demographic and Health Survey (ZDHS). Ministry of Health, Macro International Inc., Lusaka and Calverton.

[26] Kenyan Medical Research Institute (2016) CDC Research; Public Health Collaboration the Economic and Social Impacts of Maternal Death for Families in Developing Countries.

[27] ICPD or UNICPD (1994) United Nations International Conference on Population and Development (ICPD) (1994) Held in Cairo, Chapter VII-Reproductive Rights and Reproductive Health. http://www.iisd.ca/cairo.html

[28] Karlee, R. (2012) How Did Nepal Reduce the Maternal Mortality? As a Result for Analyzing the Determinants of Maternal Mortality. Journal of Medical Association, 52, 88-94. https://doi.org/10.31729/jnma.77

[29] Nasah (1994) International Conference of Population Development of 1994 (ICPD, 1994) Sexual and Reproductive Rights and Health Held in Cairo. https://www.k4health.org/sites/default/files/34-371\%20ICPD.pdf

[30] Gallant, N. and Terrisse, B. (2000) The Adolescent Mother: A Developmental or Social Concept? Department of Education, Université de Québec à Montréal, Québec.

[31] Merriam-Webster.com (2011) Hacker. http://www.merriamwebster.com/dictionary/hacker

[32] Merriam Webster Dictionary (2017). http://www.merriam-webster.com/dictionary/childbearing

[33] Valderas, J.M., Starfield, B., Sibbald, B., Salisbury, C. and Roland, M. (2009) Defining Comorbidity: Implications for Understanding Health and Health Services. Annals of Family Medicine, 7, 357-363. https://doi.org/10.1370/afm.983 
[34] Msabila, D.T. and Nalaila, S.G. (2013) Research Proposal and Dissertation Writing: Principles and Practice. Nyambari Nyangwine Publishers, Dar es salaam.

[35] Oklahoma State Department of Health (2005) Teen Pregnancy. https://www.ok.gov/health/County_Health_Departments/Choctaw_County_Health _Department/Teen_Pregnancy_Prevention/index.html

[36] Garcia, et al. (2008).

[37] Central Statistical Office (2011) Ministry of Economy, Planning and Regional Development (Cameroon), Ministry of Public Health (Cameroon), National Institute of Statistics (Cameroon), Pasteur Center of Cameroon. Cameroon Demographic and Health Survey 2011. ICF International, Fairfax.

[38] Fernandes de Azevedo, W., Diniz, B.M., Sérgio Valério, E., da Fonseca, B., Ricarte de Azevedo, M.L. and Braz Evangelista, C. (2015) Complications in Adolescent Pregnancy: Systematic Review of the Literature. Einstein (São Paulo), 13, 618-626. https://doi.org/10.1590/S1679-45082015RW3127

[39] Mukhopadhyay, P., Chaudhuri, R.N. and Bhaskar, P. (2010) Hospital-Based Perinatal Outcomes and Complications in Teenage Pregnancy in India. Journal of Health, Population and Nutrition, 28, 494-500.

https://doi.org/10.3329/jhpn.v28i5.6158 https://www.ok.gov/health/County_Health_Departments/Choctaw_County_Health _Department/Teen_Pregnancy_Prevention/index.html

[40] Althabe, F., Moore, L.J., Gibbons, L., Berrueta, M., Goudar, S.S., Chomba, E., Derman, Archana Patel, J.R., Saleem, S., Pasha, O., Esamai, F., Garces, A., Liechty, A.E., Hambidge, K.M., Krebs, F.N., Hibberd, L.P., Goldenberg, L.R., Koso-Thomas, M., Carlo, W.A., Cafferata, L.M., Buekens, P. and McClure, M.M. (2015) Adverse Maternal and Perinatal Outcomes in Adolescent Pregnancies: The Global Network's Maternal Newborn Health Registry Study. Reproductive Health, 12, S8. https://doi.org/10.1186/1742-4755-12-S2-S8

[41] Cavazos-Rehg, P.A., Krauss, M.J., Spitznagel, E.L., Bommarito, K., Madden, T., Olsen, M.A., Subramaniam, H., Peipert, J.F. and Bierut, A.J. (2015) Maternal Age and Risk of Labor and Delivery Complications. Maternal and Child Health Journal, 19, 1202-1211. https://doi.org/10.1007/s10995-014-1624-7

[42] Ahlam, A.A. (2011) Pregnancy Complication and Outcome among Teenager Al-Basrah General Hospital. Thi-Qar Medical Journal, 5, 87-93.

[43] Lao, T.T. and Ho, L.F. (1997) The Obstetric Implications of Teenage Pregnancy. Human Reproduction, 12, 2303-2305. https://doi.org/10.1093/humrep/12.10.2303

[44] Vogel, J.P., et al. (2015) Millennium Development Goal 5 and Adolescents: Looking Back, Moving Forward. Archives of Disease in Childhood, 100, s43-s47. https://doi.org/10.1136/archdischild-2013-305514

[45] Panday, S., Letsoala, T., Ranchod, C. and Makiwane, M. (2009) Teenage Pregnancy in South Africa: With a Specific Focus on School-Going Learners. Report for DBE/UNICEF.

[46] Gandanga, R. (2009) A Study to Determine the Relationship between Pregnancy and Knowledge of Pregnancy Related Complications among Adolescents Aged 13 to 19 Years in Mariner Urban. A Dissertation of the Degree of Master of Science in Nursing Science, Department of Nursing Science, College of Health Sciences, University of Zimbabwe, Harare.

[47] Mombo-Ngoma, G., Kurth, F., Schuster, K., Adegnika, A.A., Bouyou-Akotet, K.M., Kremsner, P.G. and Ramharter, M. (2010) Adolescence as Risk Factor for Adverse Pregnancy Outcome in Central Africa-A Cross-Sectional Study. PLoS ONE, 5, 
e14367.

[48] Moraes, A.M.N. (2013) Adverse Obstetric Outcomes in Adolescent Pregnancy in Rural Zambia-The Case of Kawambwa and Mansa Districts of Luapula Province. University of Zambia, Lusaka.

[49] Demographic Health Survey by CSO (2011-13) Ministry of Health, Demographic and Health Survey (ZDHS). Ministry of Health, Macro International Inc., Lusaka and Calverton.

[50] Adolescent Strategic Plan (2011-2015). Ministry of Health, Directorate of Public Health and Research, Ndeke House, Lusaka.

[51] Leppälahtil, S., Gissler, M., Mentula, M. and Heikinheimo, O. (2013) Is Teenage Pregnancy an Obstetric Risk in a Welfare Society. Department of Obstetrics and Gynecology/Kätilöopisto Hospital, University of Helsinki and Helsinki University Central Hospital, Helsinki and THL National Institute for Health and Welfare, Helsinki. http://bmjopen.bmj.com/content/3/8/e003225.full

[52] Tlebere, P.L., Jackson, D., Loveday, M., Matizirofa, L., Mbombo, N., Doherty, T., Wigton, A., Treger, L. and Chopra, M. (2010) Community-Based Situation Analysis of Maternal and Neonatal Care in South Africa to Explore Factors That Impact Utilization of Maternal Health Services.

[53] Magadi, M. (2004) Maternal and Child Health among the Urban, Poor in Nairobi. Kenya Monica Centre for Research in Social Policy (CRSP), Department of Social Sciences, Loughborough University, Loughborough.

[54] Mathole, T., Lindmark, G., Majoko, F. and Ahlberg, B.M. (2004) A Qualitative Study of Women's Perspectives of Antenatal Care in a Rural Area of Zimbabwe. Midwifery, 20, 122-132. https://doi.org/10.1016/j.midw.2003.10.003

[55] Mumtaz, Z. and Salway, S. (2005) "I Never Go Anywhere": Extricating the Links between Women's Mobility and Uptake of Reproductive Health Services in Pakistan. Social Science \& Medicine, 60, 1751-1765. https://doi.org/10.1016/j.socscimed.2004.08.019

[56] Mahy, M. (2003) Adolescent Childbearing in Sub-Saharan Africa: Can Increased Schooling Alone Raise Ages at First Birth. Demographic Research, 8, 93-106. https://doi.org/10.4054/DemRes.2003.8.4 http://www.demographic-reasearch.org/volumes/vol/8/4/8-4.pdf

[57] Raffelli, M., Bogenschneider, K. and Flood, M.F. (1998) Parent-Teen Communication about Sexual Topics. Journal of Family Issues, 19, 315-333. https://doi.org/10.1177/019251398019003005

[58] Rudra, S., Bal, H. and Singh, S. (2013) A Retrospective Study of Teenage Pregnancy in a Tertiary Care Hospital. International Journal of Reproduction, Contraception, Obstetrics and Gynecology, 2, 383-387. https://doi.org/10.5455/2320-1770.ijrcog20130924

[59] Shah, N., Khan, N., Rohra, D.K., Ahuja, L., Shuja, S., Liaqat, N.F., Kumar, K., Kumar, K., Solangi, N.A. andAzam, S.I. (2011) Comparison of Obstetric Outcome among Teenage and Non-Teenage Mothers from Three Tertiary Care Hospitals of Sindh. Department of Obstetrics and Gynecology, Civil Hospital, Karachi.

[60] Thaker, V.R., Panchal, V.M., Vyas, C.R., Shah, R.S., Shah, T.P. and Deliwala, J.K. (2012) Study of Feto-Maternal Outcome of Teenage Pregnancy at Tertiary Care Hospital. Department of Obstetrics and Gynecology, Smt. NHL Municipal Medical College, Ahmedabad.

[61] Wijesinghe, S. and Fernando, D. (2014) Maternal Perceptions of Quality of Antenatal Care Services in Sri Lanka: Development and Validation of a Multi-Dimensional 
Instrument. International Journal of Interdisciplinary and Multidisciplinary Studies, 1, 171-179.

https://www.researchgate.net/publication/273061017_Maternal_Perceptions_of_Quali ty_of_Antenatal_Care_Services_in_Sri_Lanka_Development_and_Validation_of_a Multidimensional_Instrument

[62] Debiec, et al. (2010).

[63] Kyei, N.N.A., Chansa, C. and Gabrysch, S. (2012) Quality of Antenatal Care in Zambia: A National Assessment. BMC Pregnancy and Childbirth, 12, 151. https://doi.org/10.1186/1471-2393-12-151

[64] Tilghman, J. and Lovette, A. (2008) Prenatal Care: The Adolescent's Perspective. The Journal of Perinatal Education, 17, 50-53. https://doi.org/10.1624/105812408X298390

[65] WHO (2014) Zambia Regional Office for Africa. http://www.aho.afro.who.int/profiles_information/index.php/Zambia:The_Health_ System

[66] The National Teenage Pregnancy Midwifery Network (2015) The National Teenage Pregnancy. Midwifery Network at Best Beginnings Has a Collection of Policy and Practice Resources, Including Care Pathways for Young Parents.

http://www.bestbeginnings.org.uk/ntpmn

[67] Hueston, W.J., Geesey, M.E. and Diaz, V. (2008) Prenatal Care Initiation among Pregnant Teens in the United States: An Analysis over 25 Years. Journal of Adolescent Health, 42, 243-248. https://doi.org/10.1016/j.jadohealth.2007.08.027

[68] Smith, G.C.S. and Pell, J.P. (2001) Teenage Pregnancy and Risk of Adverse Perinatal Outcomes Associated with First and Second Births: Population Based Retrospective Cohort Study. British Medical Journal, 323, 476-479.

https://doi.org/10.1136/bmj.323.7311.476

[69] Alan Guttmacher Institute (1997) Risks and Realities of Early Child Bearing Worldwide.

[70] Saba, N., Hamayun, M. and Bilal, M. (2013) Outcome of Teen Age Pregnancy. Biomedica, 29, 27-31.

[71] Hennekens, C. and Hand Buring, J.E. (1987) Introduction to Study Designs-Geographical Epidemiology in Medicine. Lippincott Williams and Wilkins, Philadelphia.

[72] Etikan, I., Abukabah, M.S. and Alkassim, S.R. (2015) Comparison of Convenience Sampling and Purposeful Sampling. American Journal of Theoretical and Applied Statistics, 5, 1-4. https://doi.org/10.11648/j.ajtas.20160501.11

[73] Labaree, R. (2017) Cross Sectional Design-Research Methods in Social SciencesLibrary at Lynn University.

[74] Mosha, T.C.E. and Philemon, N. (2010) Factors Influencing Pregnancy Outcomes in Morogoro Municipality, Tanzania. Tanzania Journal of Health Research, 12, 249-260. https://doi.org/10.4314/thrb.v12i4.51795

[75] National Fetal-Infant Mortality Review Program (2007) Data Abstraction Form: National Fetal and Infant Mortality Review Program. American College of Obstetricians and Gynecologists and the Maternal and Child Health Bureau, Health Services and Resource Administration, Washington DC.

https://www.ncfrp.org/wp-content/uploads/NCRPCD-Docs/FIMRDataAbstraction Book.pdf

[76] Ministry of Health (2012) National Health Policy. Ndeke House, Lusaka. 
[77] Paarlberg, K.M., Vingerhoets, A.D. and Van Geijn, H.P. (2006) Maternal Stress and Labor. In: Kurjak, A. and Chervenak, F.A., Eds., Textbook of Perinatal Medicine, 2nd Edition, Chapter 188, Taylor \& Francis, Abingdon-on-Thames, 1998-2005. https://www.researchgate.net/publication/242025008_Maternal_Stress_and_Labor

[78] Wadhawan, S., Narone, R.K. and Narone, J.N. (1982) Obstetric Problems in the Adolescent Zambian Mother Studied at the University Teaching Hospital, Lusaka. Medical Journal of Zambia, 16, 65-68.

[79] Sandoy, I.F. (2015) CISMAC Study to Examine Links between Adolescent Pregnancies and Different Approaches to Empower Adolescent Girls, Lusaka, Zambia.

[80] Obossou, A.A.A., et al. (2015) Management of Pregnancy and Childbirth among Adolescents at the Regional University Teaching Hospital of Parakou. Clinics in Mother and Child Health, 12, 4. https://doi.org/10.4172/2090-7214.1000198

[81] Wedekind, V. and Tomaida, M. (2015) Second Chances for Girls: The Zambian Re-Entry into School Policy. http://www.bioline.org.br/pdf?ep04041 
Appendix: Interview Schedule

THE UNIVERSITY OF ZAMBIA

SCHOOL OF NURSING SCIENCES

RIDGEWAY CAMPUS

STRUCTURED INTERVIEW SCHEDULE

TITLE: COMMON CHILDBIRTH COMPLICATIONS AMONG ADOLESCENTS MOTHERS AT MBALA GENERAL HOSPITAL
Institution
Province.
Date of collection of data
Period.
Researchers' Name.
Files' serial number
Ward.

\section{INSTRUCTIONS}

1) Introduce yourself to the respondent

2) Explain the purpose of the interview to the respondent

3) Assure respondent of confidentiality and anonymity

4) Obtain verbal consent to interview her

5) Do not write the name of the respondent on interview schedule instead indicate file number

6) Tick in the box corresponding to the correct answer with alternative

7) Write responses and observations in spaces provided for open questions

\section{SECTION A: CHILDBIRTH COMPLICATIONS OFFICIAL USE ONLY}

\section{i. Antepartum Haemorrhage}

1) Was the patient admitted with one of the following complications below? (Please tick any correct response observed or documented in the patients' file).

i) Ante Partum Haemorrhage due to (click what is applicate)
a) Placenta previa
\{\}
b) Placenta abruptio
c) Trauma (falling/ART)
ii) Pre-term Labour
iii) Pre Rupture of Membranes
iv) Severe pre-eclampsia
\{\}
v) Any other specify

\section{ii. Intrapartum Phase \& Complications}

2) How long was your labour on this baby just delivered?

i) $6-8$ hours 

ii) 8 - 10 hours
\{\}
iii) 11 - 12 hours
iv) More than 18 hours
\{\}

3) Did the patient develop any of the following complications? Mark what is applicable.
i) Cord prolapse
ii) Ruptured uterus
iii) Maternal distress
iv) Cephalo-Pelvic Disproportion (CPD) \{\}
v) Any other specify

4) What caused the condition being referred to in 19 ?
i) Transverse
\{\}
ii) Breech presentation
iii) Compound presentation
iv) Big baby
\{\}
v) Any other specify

\section{iii. Postpartum Phase \& Complications}

Tick any of the complications you have observed or are documented in the patient's file.

5) Post-Partum Hemorrhage due to
a) Atonic uterus
b) Retained Placenta / products \{\}
c) DIC
d) Third degree / perineal tears \{\}
e) Fistulae
f) Severe Eclampsia
g) Maternal death
h) Any other (specify)

6) What intervention was applied to assist in delivery? (Tick one)
a) Spontaneous Vaginal Delivery
\{\}
b) SVD with episiotomy
\{\}
c) Caesarean section
\{\}
d) Vacuum extraction

7) Who conducted the delivery?
i) Midwife
ii) General Nurse
\{\}
iii) Medical Officer General
iv) Obstetrician
\{\}

8) Where was the partograph opened to monitor progress of labour
a) Health Post
\{\}
b) Health centre
\{\}
c) Clinic
\{\} 

d) Hospital
\{\}

9) What is the condition of the baby at delivery?
i) Asphyxiated
\{\}
ii) Stillbirth
\{\}
iii) Alive-mature
\{\}
iv) Alive-premature

10) What is the baby' Apgar score at birth?
a) 3 - 5 at minute
b) 6 - 7 at 1 minute
c) 8 - 9 at 1 minute
d) Cried spontaneous at delivery

11) What is the weight of the baby?
i) Less than $2500 \mathrm{~g}$
ii) $2500 \mathrm{~g}-2900 \mathrm{~g}$
iii) 3000 - $3500 \mathrm{~g}$
iv) More than $3500 \mathrm{~g}$

\section{SECTION B: SOCIO-DEMOGRAPHIC CHARACTERISTICS}

12) What is your age? (Age on last birthday) years

13) Where do you stay?
a) Urban
b) Rural
c) Mpulungu
d) Nsenga
e) Tanzania

14) What is your marital status?
i) Single
ii) Married
iii) Divorced
iv) Separated
v) Widowed

15) What is your religion?
a) Roman Catholic
\{\}
b) United Church of Zambia
\{\}
c) $\mathrm{SDA}$
\{\}
d) Reformed Church of Zambia
\{\}
e) Others (Specify)

16) What is your highest educational attainment?
a) Never been to school
\{\}
b) Primary
c) Secondary
d) College
e) University 
17) What is your occupation?
i) Self-employed
ii) Formal employment
iii) Farmer
iv) Full-time housewife
\{\}

18) How many pregnancies have you had?

19) How many of these pregnancies did reach term?

20) How many children do you have?

21) What was the gestational age of the baby just delivered?

22) How many ANC visits did you attend on this baby just delivered?
i) Non
\{\}
ii) 1 - 2 visits
\{\}
iii) 3 - 4 visits
iv) More than 4 visits
\{\}

23) Where were you doing your ANC on this baby just delivered?
i) Health post
\{\}
ii) Health Centre
\{\}
iii) Clinic static
iv) Mobile Clinic
\{\}

24) At what gestational age did you start ANC on this baby just delivered?
i) 1 - 3 months
\{\}
ii) 4 - 5 months
iii) 6 - 7 months
iv) 8 - 9 months
\{\}

25) How did you come to this institution?

i) Referred by health care personnel \{\}

ii) Self-referral

iii) Normal admission

iv) Emergency

26) If referred, who referred you?
i) Midwife or DEM
\{\}
ii) General Nurse
iii) Environmental health technician \{\}
iv) Supportive staff (CDE/CHA) $\quad\{\}$
v) Any other specify

27) What is the prevalence of maternal age associated with child birth complications among adolescent mothers who gave birth at Mbala General Hospital?

i) Below 17 years

ii) 18 - 19 years

\section{SECTION C: Co-morbidities}

28) Does the patient have any co-morbidity \{other condition) (s)\} (Tick if indicated in the file) 


$\begin{array}{ll}\text { i) Malaria } & \{\} \\ \text { ii) Aneamia } & \{\} \\ \text { iii) HIV Positive } & \{\} \\ \text { iv) Urinary Tract Infection (UTI) } & \{\} \\ \text { v) Diabetes Mellitus } & \{\} \\ \text { vi) Others specify } & \end{array}$

vi) Others specify 